\title{
Role of wave cyclones in transporting boundary layer air to the free troposphere during the spring 2001 NASA/TRACE-P experiment
}

\author{
John R. Hannan and Henry E. Fuelberg \\ Department of Meteorology, Florida State University, Tallahassee, Florida, USA
}

James H. Crawford and Glen W. Sachse

NASA Langley Research Center, Hampton, Virginia, USA

Donald R. Blake

University of California, Irvine, Irvine, California, USA

Received 31 October 2002; revised 15 April 2003; accepted 16 April 2003; published 23 September 2003.

[1] Transport of boundary layer air to the free troposphere by cyclones during NASA's Transport and Chemical Evolution over the Pacific (TRACE-P) experiment is investigated. Airstreams responsible for boundary layer venting are diagnosed using results from a high-resolution meteorological model (MM5) together with in situ and remotely sensed chemical data. Hourly wind data from the MM5 are used to calculate three-dimensional grids of backward air trajectories. A reverse domain filling (RDF) technique then is employed to examine the characteristics of airstreams over the computational domain, and to isolate airstreams ascending from the boundary layer to the free troposphere during the previous 36 hours. Two cases are examined in detail. Results show that airstreams responsible for venting the boundary layer differ considerably from those described by classic conceptual models and in the recent literature. In addition, airstreams sampled by the TRACE-P aircraft are found to exhibit large variability in chemical concentrations. This variability is due to differences in the boundary layer histories of individual airstreams with respect to anthropogenic sources over continental Asia and Japan. Complex interactions between successive wave cyclones also are found to be important in determining the chemical composition of the airstreams. Particularly important is the process of post-cold frontal boundary layer air being rapidly transported offshore and recirculated into ascending airstreams of upstream cyclones. INDEX TERMS: 0368 Atmospheric Composition and Structure: Troposphere-constituent transport and chemistry; 3329 Meteorology and Atmospheric Dynamics: Mesoscale meteorology; 3364 Meteorology and Atmospheric Dynamics: Synoptic-scale meteorology; KEYWORDS: boundary layer, chemical transport, mesoscale modeling, wave cyclones

Citation: Hannan, J. R., H. E. Fuelberg, J. H. Crawford, G. W. Sachse, and D. R. Blake, Role of wave cyclones in transporting boundary layer air to the free troposphere during the spring 2001 NASA/TRACE-P experiment, J. Geophys. Res., 108(D20), 8785, doi:10.1029/2002JD003105, 2003.

\section{Introduction}

[2] Understanding the mechanisms by which pollution is transported from the Asian continent during spring was a major goal of NASA's Transport and Chemical Evolution over the Pacific (TRACE-P) aircraft campaign [Jacob et al., 2003], a component of the Global Tropospheric Experiment (GTE) [McNeal et al., 1984] that was conducted during February-April 2001. Extratropical wave cyclones are of particular interest since their associated airstreams are thought to be the dominant mode of tropospheric trace gas transport [Cotton et al., 1995; Donnell et al., 2001; Stohl, 2001] and tropospheric-stratospheric exchange in the

Copyright 2003 by the American Geophysical Union. 0148-0227/03/2002JD003105\$09.00 midlatitudes [Holton et al., 1995]. These airstreams are responsible for transporting polluted air out of the boundary layer and injecting ozone-rich stratospheric air into the free troposphere. Although the subject of stratospheric-tropospheric exchange has received extensive attention, less is known about the processes of trace gas transport from the boundary layer to the free troposphere [Bethan et al., 1998]. A greater understanding is needed since polluted boundary layer air lifted to higher altitudes can perturb natural chemical concentrations, impact the global radiation budget, and affect air quality at distant locations downstream.

[3] The role of cyclones in transporting pollution across the Atlantic from the eastern United States to Europe has been the focus of various recent studies [e.g., Bethan et al., 1998; Stohl and Trickl, 1999; Cooper et al., 2001; Stohl, 2001], owing to the potential chemical impact of the United 
States on European air quality and the relatively large number of aircraft campaigns in the region. However, the role of cyclones in transporting pollution from the rapidly industrializing regions of eastern Asia to the western Pacific and beyond has received much less attention. Kaneyasu et al. [2000] used a chemical transport model and backward trajectories to describe the episodic emergence of polluted boundary layer air over the eastern Pacific Ocean due to the passage of cold fronts during winter. They found that the offshore movements of cold fronts acted as "gates," allowing previously stagnant continental air to move offshore, carrying with it the chemical characteristics of its source region. They further speculated that transport from the continent likely occurred most often during spring when the frequency of such systems over the Asian pollution source regions is a maximum. Long-range transport over the Pacific during spring was examined by Martin et al. [2002]. Trajectories calculated from global reanalysis data resolved a polluted "river" originating over Asia and its "tributaries" from the Americas. Results showed that midlatitude outflow from the Asian continent could ultimately affect remote areas of the tropical Pacific Ocean after up to 25 days of transit. Jaffe et al. [1999] used trajectories and chemical data to explain elevated concentrations of Asian chemicals over northwestern Washington State. However, the limited spatial nature of the observed chemical data and the small number of trajectories yielded little information about the role of cyclones in the overall transport process.

[4] A thorough understanding of the role of wave cyclones and their airstreams in transporting pollution from Asia has not yet been achieved. This is a concern since many areas in eastern Asia are in the early stages of a major industrial revolution. Energy use in this region, mostly from fossil fuel burning, has increased by $5 \%$ over the last decade and is expected to continue at this rate for the next 2 decades [U.S. Department of Energy, 1997]. Clearly, this trend will have important impacts on tropospheric chemistry at local, regional, and global scales.

[5] The quasi-Lagrangian (system relative) flow within moving mid-latitude cyclones often is described with simple conceptual models. Early models [e.g., Browning and Harrold, 1969; Carlson, 1980; Browning and Mason, 1981] consisted of three major airstreams (Figure 1). In these early models the warm conveyor belt (WCB) is a warm moist flow that ascends from the boundary layer and lower troposphere ahead of the surface cold front. Once poleward of the surface warm front, the WCB turns anticyclonically toward the east. The cold conveyor belt (CCB) is a weaker flow, often confined to lower levels and generally flowing from east to west on the cold side of the surface warm front. The CCB flows under the WCB and ascends anticyclonically to the northwest of the surface low pressure, similar to the WCB. Finally, the dry intrusion (DI) is a descending flow, confined primarily behind the surface cold front, which inhibits cloud formation and is the source of the "dry slot" often seen in satellite water vapor imagery. Browning [1986, 1990] gives additional details about the cyclone model, including the organization of clouds and precipitation in these systems

[6] Several recent studies have suggested modifications to the classic cyclone model to include cyclonic appendages to the WCB and/or CCB airstreams (Figure 1) not in the

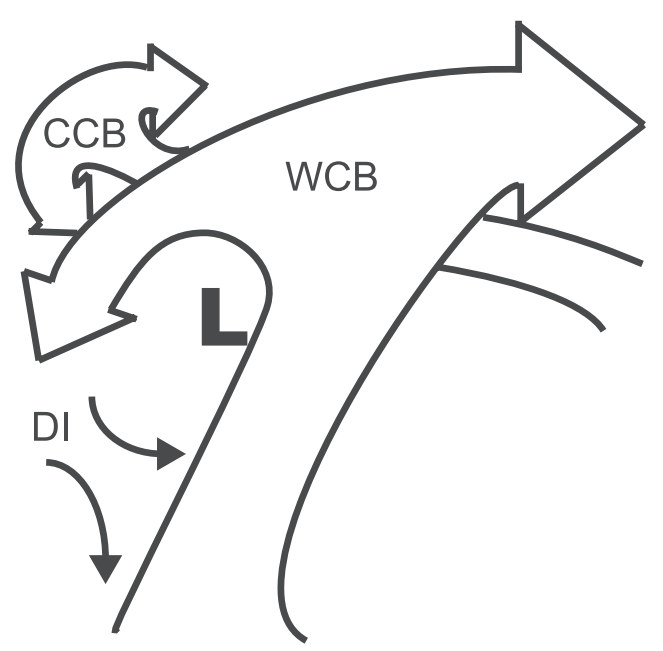

Figure 1. Midlatitude cyclone airstream configuration. Airstreams are the warm conveyor belt (WCB), cold conveyor belt (CCB), and dry intrusion (DI). The surface low-pressure center is indicated with $\mathrm{L}$.

classical description [Young, 1989; Bader et al., 1995; Cooper et al., 2001; Schultz, 2001]. Kuo et al. [1992], however, found no basis for identifying conveyor belts based on temperature or moisture contrasts when modeling an occluded marine cyclone. Rather than two distinct airstreams representing warm and cold conveyor belts, they found a "fanlike" spreading of ascending air north of the cyclone center. Mass and Schultz [1993] reached a similar conclusion in their study of a cyclone over land. As with Kuo et al. [1992], they were unable to isolate three major airstreams in the classic sense, but instead concluded that trajectories could be meaningfully grouped into a limited number of "families."

[7] Advancements in computing capabilities have allowed studies that classify airstreams and conveyor belts by imposing appropriate objective criteria on large grids of trajectories. This procedure isolates groups of trajectories having similar properties and/or histories. For example, Wernli and Davies [1997] selected a combination of strong ascent, large decreases in specific humidity, small values of potential vorticity, and large increases in potential temperature along backward trajectory paths to be indicators of warm conveyor belts. Using these criteria they identified "coherent ensembles of trajectories" (CETs) having extensive vertical depths, noting that they did not directly equate to conveyor belts.

[8] While developing a 1-year climatology of northern hemispheric airstreams, Stohl [2001] specified criteria for WCBs based on the ascent rates of forward trajectories over a particular period of time and from certain vertical locations. Like the studies by Wernli [1997] and Wernli and Davies [1997], Stohl [2001] used strict criteria that only identified "strong" conveyor belts. Shallow flows that transferred air from the boundary layer to the free troposphere were not considered. Using a similar method, Esler and Haynes [2003] examined Lagrangian air mass properties across cold fronts via the reverse-domain-filling technique (RDF) [Sutton et al., 1994]. Their method employed trajectories that were calculated with both mesoscale and 
global model data. The results were used with aircraft and ground based chemical data to examine the chemical transport and mixing of air masses near cold fronts over the United Kingdom.

[9] The techniques just described take advantage of modern computing capabilities to analyze atmospheric motions with much more precision than in the past. They also eliminate the time consuming and subjective processes of manually analyzing large numbers of trajectories and/or numerous instantaneous fields at various times and altitudes. Their only significant sensitivity is the time interval of the required wind data. Wind data at 1-hour temporal resolution were found necessary to appropriately diagnose synoptic scale airstreams, particularly those near the surface [Cohen and Kreitzberg, 1997].

[10] The current study has two primary goals: (1) to understand the transport of boundary layer air into the free troposphere by mid-latitude cyclones during TRACE-P, and (2) to investigate the chemical characteristics of the airstreams responsible for this transport. We examine two days from TRACE-P to reach these goals. Potentially polluted, ascending airstreams are identified using the RDF technique and then discussed in the context of their meteorological histories based on backward trajectories. The previously discussed terminologies used to describe ascending airstreams (i.e., WCB, CCB, CET, etc.) are avoided since we do not discriminate between flows based on criteria associated with classic cyclone structure theory (e.g., vertical depth). When applicable, however, parallels are drawn between the observed airstreams and those presented in the literature. This research differs from previous airstream studies by concentrating on ascending airstreams from the boundary layer, where the bulk of anthropogenic pollution originates, regardless of their vertical extent.

[11] Section two follows with a detailed discussion of the meteorological and chemical data and the methodologies that were used. This is followed by two sections detailing the synoptic environment, modeling results, and interpretation of chemical data on two TRACE-P flight days. Finally, a summary is given, and major findings are discussed.

\section{Methodology and Data}

\subsection{Meteorological Data}

[12] We used the Fifth-Generation National Center for Atmospheric Research/Pennsylvania State University Mesoscale Model (MM5) to generate the hourly meteorological data needed for this study. MM5 is a nonhydrostatic, primitive equation model that is fully described by Anthes and Warner [1978], Dudhia [1993], and Grell et al. [1994].

[13] Model domains for the two simulation periods were positioned over eastern Asia and the Pacific Basin but extended well beyond this region to reduce the effects of boundary error propagation into the areas of interest [Warner et al., 1997]. The grids for all simulations had $90 \mathrm{~km}$ horizontal separation and utilized 40 vertical sigma levels. Fifteen of these levels had $10 \mathrm{hPa}$ separation below $850 \mathrm{hPa}$ (approximately within the boundary layer) to provide enhanced vertical resolution at low altitudes. Within the middle free troposphere, the vertical grid spacing was stretched to $\sim 25 \mathrm{hPa}$ up to an altitude of $\sim 400 \mathrm{hPa}$. Above $400 \mathrm{hPa}$ the grid spacing was $\sim 50 \mathrm{hPa}$, with the top of the model being $100 \mathrm{hPa}$.

[14] Model physical and dynamical parameterization schemes were identical for both simulations. We used the Blackadar high-resolution planetary boundary layer scheme [Zhang and Anthes, 1982], the Anthes-Kuo cumulus parameterization scheme [Anthes, 1977], and a simple ice microphysical scheme to represent saturated processes.

[15] Initial and lateral boundary conditions for MM5 were obtained from three-dimensional (3-D) global reanalyses prepared by the National Center for Environmental Prediction (NCEP) and available from the National Center for Atmospheric Research (NCAR). These data were at 12-hour intervals and $2.5^{\circ}$ horizontal resolution. Two-dimensional data sets specifying sea surface temperatures also were obtained from NCEP, while land use and terrain characteristics were acquired from NCAR. Four-dimensional data assimilation (FDDA) was employed to relax the model solutions toward the synoptic analyses, thus ensuring the correct placement of features of interest and effectively reducing model error growth [Stauffer and Seaman, 1990; Stauffer et al., 1991; Stauffer and Seaman, 1994; Seaman and Michelson, 2000]. Data from the first 12 hours of the simulations were not used to allow sufficient model spin up time.

[16] Numerous MM5-derived fields were compared to global analyses, satellite imagery, and aircraft measured meteorological fields to verify the quality of the simulations. Close agreement was found in all cases with respect to the placement, intensity, and propagation of major meteorological features. Similarly, the magnitudes of various parameters (e.g., wind speed and direction, temperature, humidity, etc.) also showed close agreement with the global analyses and aircraft measured variables. For the sake of brevity, only the modeled wind speeds versus those measured at 1-min intervals during all flights used in this study are shown here (Figure 2). Very good agreement is found between the two data sets, with the largest discrepancies occurring at upper levels (wind speeds $>\sim 40 \mathrm{~m} \mathrm{~s}^{-1}$ in Figure 2), owing to intense gradients near the polar jet streams that were intersected by the aircraft. Nevertheless, overall performance of the model is excellent, yielding an $\mathrm{R}^{2}$ value of 0.905 .

[17] We used the hourly wind data from MM5 to calculate backward air trajectories out to 3.5 days. Doty and Perkey [1993] showed that hourly wind data are needed to ensure the reliability of trajectories, thereby eliminating our use of coarser global analyses (typically 6-hourly) provided by the national centers. Trajectories were constructed via the kinematic method. That is, the $3-\mathrm{D}$ wind fields were used to advect air parcels, while ignoring the isentropic assumption. Limitations of trajectories include incorrect placement of meteorological features by the input data, insufficient spatial and temporal resolution of the wind data, and numerical limitations of the calculations themselves [Draxler, 1991; Stohl et al., 1995; Stohl and Seibert, 1998]. Nonetheless, kinematic trajectories have been widely used in many recent chemical transport studies [Bieberbach et al., 2000; Fuelberg et al., 2000; Hannan et al., 2000; Stohl et al., 2001; Esler and Haynes, 2003] and are considered superior to their isentropic counterparts, particularly in areas where diabatic effects are significant. A thorough comparison of the kine- 


\section{All Flights - Model vs Aircraft Wind Speed $(\mathrm{m} / \mathrm{s})$}

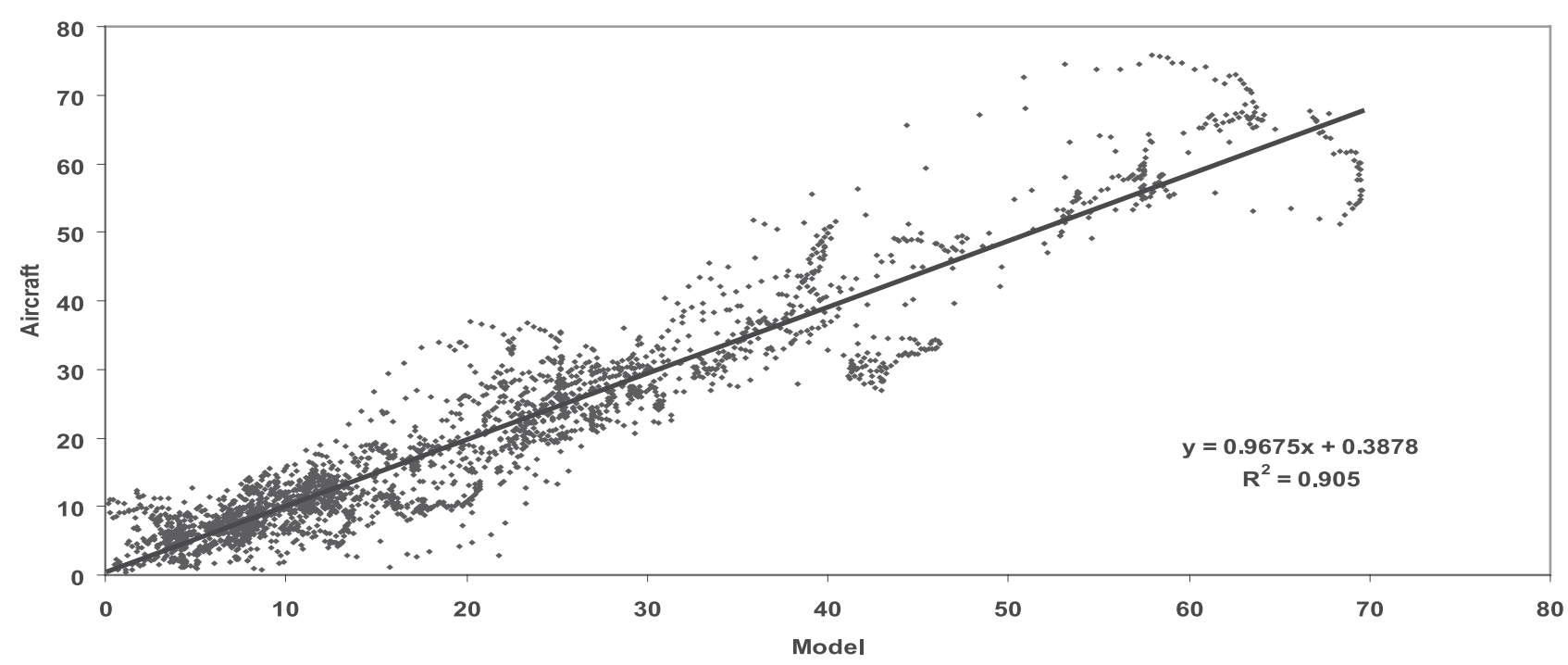

Figure 2. MM5-derived versus aircraft measured wind speed $\left(\mathrm{m} \mathrm{s}^{-1}\right)$ at 1-min intervals along all flights used in this study.

matic and isentropic methods as well as a complete description of the trajectory model used in this study can be found in the work of Fuelberg et al. [1996].

[18] Our backward trajectories were launched from 3-D grids of arrival positions over features of interest. These arrival locations were separated horizontally by $0.5^{\circ}$ latitude and longitude, with a vertical separation of $25 \mathrm{hPa}$. The 3-D trajectory grids were calculated backward in time for 3.5 days or until they left the computational domain. Information along the trajectory paths, including latitude, longitude, pressure height, and 3-D wind components was saved each hour.

[19] Utilizing the trajectory grids, reverse-domain-filling (RDF) [Sutton et al., 1994] was employed to interpret the chemical and meteorological data. The technique involves mapping time dependent quantities calculated along each trajectory path back to that trajectory's initial position. Specifically, for each trajectory within our grids, pressure altitude information was mapped back to the trajectory's arrival point. We believe that the RDF technique presents a more effective visualization of airstream evolution than is possible using trajectories alone. More details about this procedure follow in section 3.2.

[20] Additional backward air trajectories were calculated at 1-min intervals of flight time from positions of the DC-8 and P-3B aircraft, corresponding to approximately $10 \mathrm{~km}$ separation between adjacent trajectories, depending on aircraft speed. The trajectories arrived at the hour closest to the actual times of the in situ chemical measurements. Visible, infrared, and water vapor imagery from the GMS-5 satellite were used to validate model results and identify meteorological features associated with transport processes.

\subsection{Chemical Data}

[21] We used in situ chemical data from the DC-8 and P-3B aircraft in the study. These data were at various temporal resolutions due to differing response times of the measuring devices. The data were interpolated to $1-\mathrm{min}$ intervals and combined into "merged" data sets prepared at NASA Langley Research Center. These data sets contain information about a suite of radiatively important species, photochemical oxidants, sulfur, aerosols, and a host of air mass tracer species. They also include meteorological measurements and aircraft position data. Jacob et al. [2003] discuss the various species measured, as well as the instruments, techniques, and limits of detection.

\section{21 March 2001 Cyclones: DC-8 Flight 13-P-3B Flight 15}

[22] Conceptual models are useful tools for understanding general flow patterns within midlatitude cyclones. However, actual airstream configurations in a given cyclone may be more complex than in the models, the product of the system's unique evolution and structure. As a result, chemical transport will vary between systems. This section examines the multifaceted arrangement of airstreams within a family of cyclones over eastern Asia and the northwest Pacific on 21 March 2001. The cyclones were in various stages of development and exhibited diverse transport pathways from the boundary layer to the free troposphere. NASA's P-3B and DC-8 aircraft sampled several of these rising airstreams during flights from Yokota Air Base, Japan, providing important chemical information about their potential roles in pollution transport.

\subsection{Synoptic Environment}

[23] Figure 3 depicts MM5 forecasts of sea level pressure at 24-hour intervals between 0000 UTC 18 March and 0000 UTC 21 March 2001. Several cyclones are evident over the western North Pacific and adjacent eastern Asia on 21 March, the day of the flights (Figure 3d). Most notable is a strong low-pressure system that resulted from the merger of a mature cyclone (cyclone 1 , hereafter $\mathrm{C} 1$ ) with a decaying occluded system (cyclone 2 , hereafter $\mathrm{C} 2$ ). The cold front of $\mathrm{C} 1 / \mathrm{C} 2$ is east of the eastern Japanese coastline 
A)

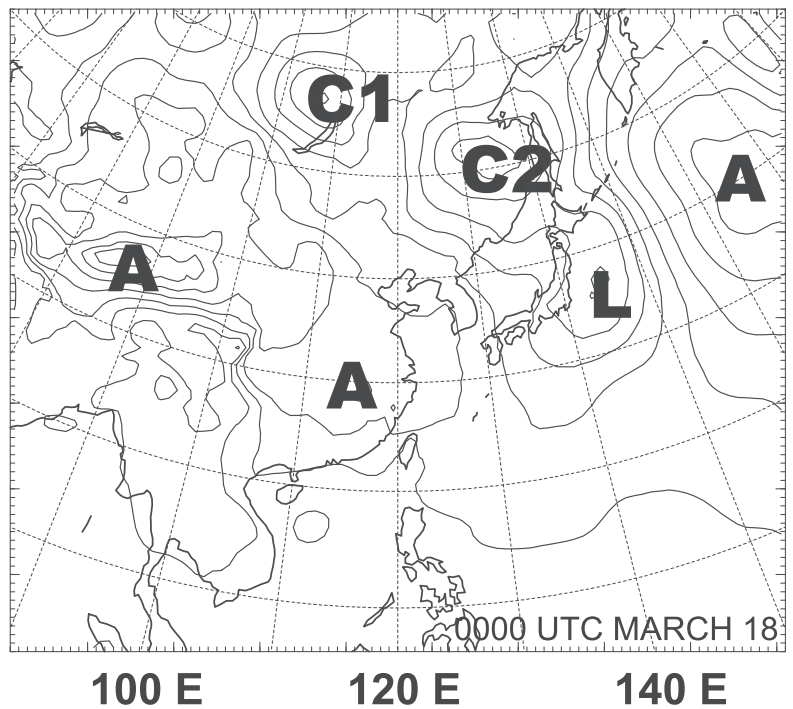

C)

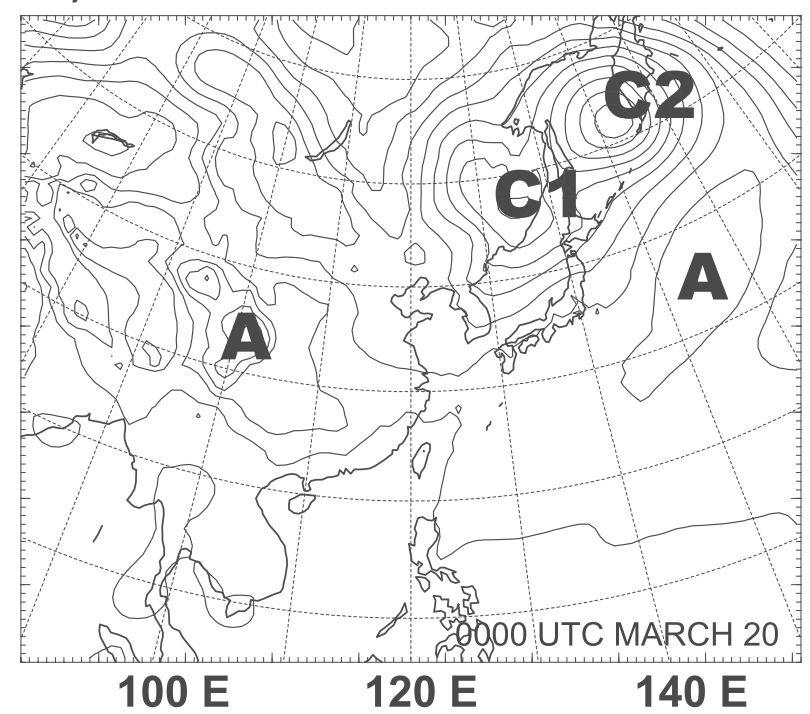

B)

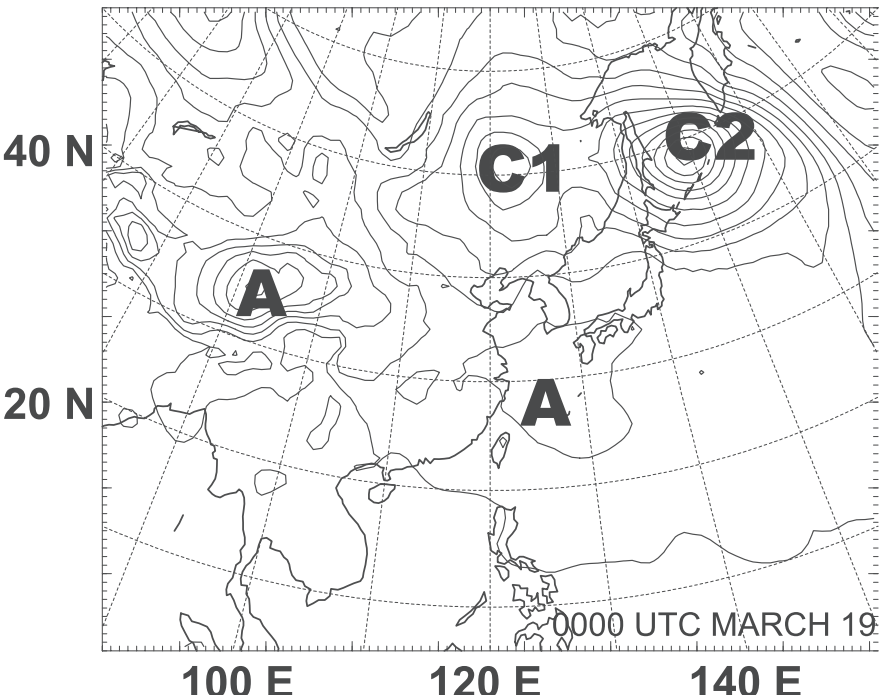

D)

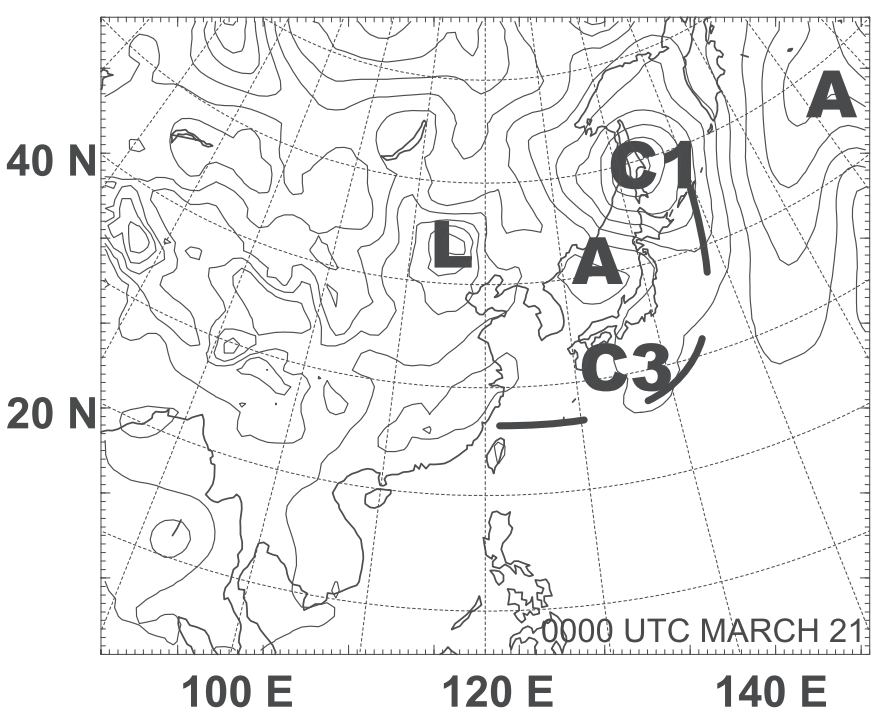

Figure 3. MM5 sea level pressure forecast for (a) 0000 UTC 18 March $(F+48)$, (b) 0000 UTC 19 March (F + 72), (c) 0000 UTC 20 March (F + 96), and (d) 0000 UTC 21 March (F + 120). Positions of cyclone centers are indicated by $\mathrm{C} 1, \mathrm{C} 2$, and $\mathrm{C} 3$. L and $\mathrm{A}$ indicate positions of other cyclone and anticyclone centers. The position of the cold front crossed by the P-3B and DC-8 is indicated by the dashed curve in Figure 3d.

and extends southwest to near Taiwan. In addition, a weak wave (cyclone 3, C3) is beginning to form along the front south of Japan $\left(\sim 30^{\circ} \mathrm{N}, 138^{\circ} \mathrm{E}\right)$. Looking back in time, $\mathrm{C} 1$ originated over the Siberian Plateau $\left(\sim 55^{\circ} \mathrm{N}, 110^{\circ} \mathrm{E}\right)$ near 0000 UTC 18 March (Figure 3a) and emerged into the northernmost Sea of Japan at $\sim 0000$ UTC on 20 March (Figure 3c). Over the next 24 hours, the low-pressure center slowly moved toward the north/northeast where it merged with the occluded $\mathrm{C} 2$ cyclone.

\subsection{Isolation of Vented Boundary Layer Air}

[24] The vertical transport of boundary layer air by the cyclones on 21 March is revealed by the 36-hour reverse domain filling (RDF) technique (Figure 4). The 36-hour computational period is within the range required for air to pass through synoptic systems [Stohl, 2001]. Boundary layer transport to the four altitudes $(700,600,500$, and $400 \mathrm{hPa}$ ) is based on maximum pressure during the previous 36 hours. Specifically, the plots were constructed from the grids of backward trajectories calculated from hourly $90 \mathrm{~km}$ MM5 wind data, i.e., backward from the four pressure levels listed above. For each trajectory at each altitude the maximum pressure (minimum height) over the previous 36 hours was mapped back to the trajectory's initial position. Since we define the boundary layer as that region below $850 \mathrm{hPa}$, only areas of maximum 36-hour RDF pressure greater than $850 \mathrm{hPa}$ are shaded in Figure 4. The choice of $850 \mathrm{hPa}$ as the top of the boundary layer is necessarily subjective. Actual boundary layer heights vary considerably due to surface characteristics (land, water, 

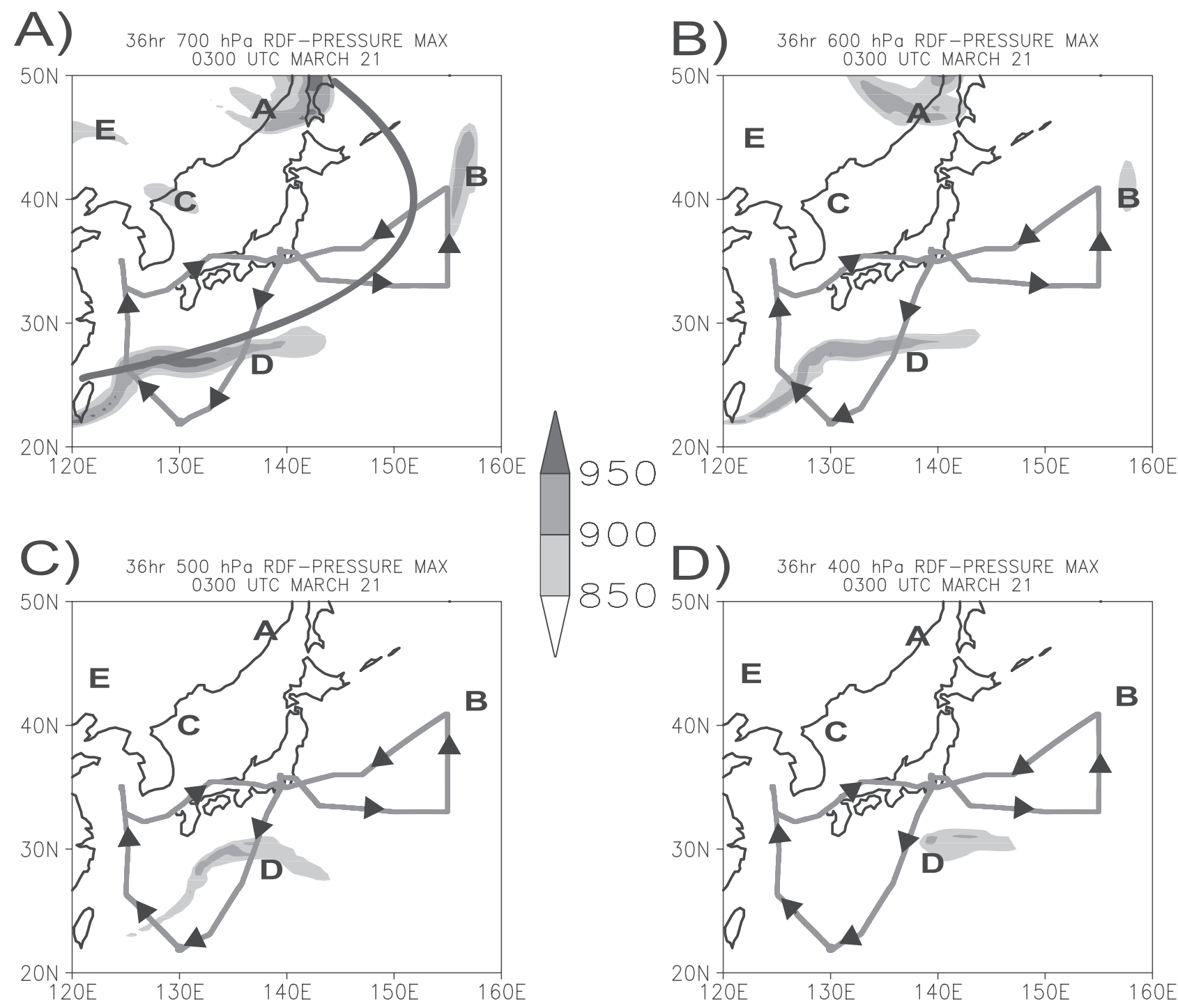

Figure 4. Reverse domain filling (RDF) of 36-hour maximum pressure (hPa) at 0300 UTC 21 March 2001 for (a) $700 \mathrm{hPa}$, (b) $600 \mathrm{hPa}$, (c) $500 \mathrm{hPa}$, and (d) $400 \mathrm{hPa}$. Shaded regions indicate air with a boundary layer history. Flight tracks (arrows) and surface cold front position (curved line) are indicated.

vegetation, soil moisture, etc.), horizontal wind, stability, time of the day, and topography. Nevertheless, this isolation of previously boundary layer air based on 36-hour altitude history allows airstreams important for pollution transport to be identified without specifying their vertical depth or location with respect to cyclone features.

[25] The RDF technique reveals that five regions associated with the aforementioned cyclones are influenced by boundary layer venting during the previous 36 hours (areas $\mathrm{A}-\mathrm{E}$ in Figures $4 \mathrm{a}-4 \mathrm{~d}$ ). The regions labeled $\mathrm{A}, \mathrm{B}, \mathrm{C}$, and $\mathrm{E}$ correspond to ascent related to cyclones $\mathrm{C} 1 / \mathrm{C} 2$, while region $\mathrm{D}$ is associated with $\mathrm{C} 3$.

[26] A schematic of the backward trajectories responsible for regions $\mathrm{A}-\mathrm{E}$ is shown in Figure 5. These trajectory illustrations are in an earth-relative coordinate system as opposed to the storm-relative frame of reference used to describe airstreams in most conceptual models (e.g., Figure 1). Therefore our trajectory paths do not directly equate to the airstream paths depicted in the models.
However, this difference is not a major concern since the altitudes of airstreams are most important to this study.

[27] It is clear that the airstreams associated with transport of boundary layer air to the free troposphere exhibit a complex arrangement (Figure 5). Regions A, C, and E are discussed first. Although the aircraft did not sample these three regions, their airstreams have interesting paths and potentially important chemical transport capabilities. Sampled regions $\mathrm{B}$ and $\mathrm{D}$ are discussed in later sections.

\subsection{Region A: Cyclone Center}

[28] The ascent of boundary layer air comprising region $\mathrm{A}$ (Figure 4) is due to cyclones C1 and C2. Air with a 36-hour boundary layer history extends only to $\sim 600 \mathrm{hPa}$ in this area near the surface center of $\mathrm{C} 1$. The transport of boundary layer air to $\mathrm{A}$ is not the result of a single flow but rather a complex integration of three airstreams (A1, A2, and A3) (Figure 5) that are not easily delineated due to the merger of $\mathrm{C} 1$ and $\mathrm{C} 2$. 

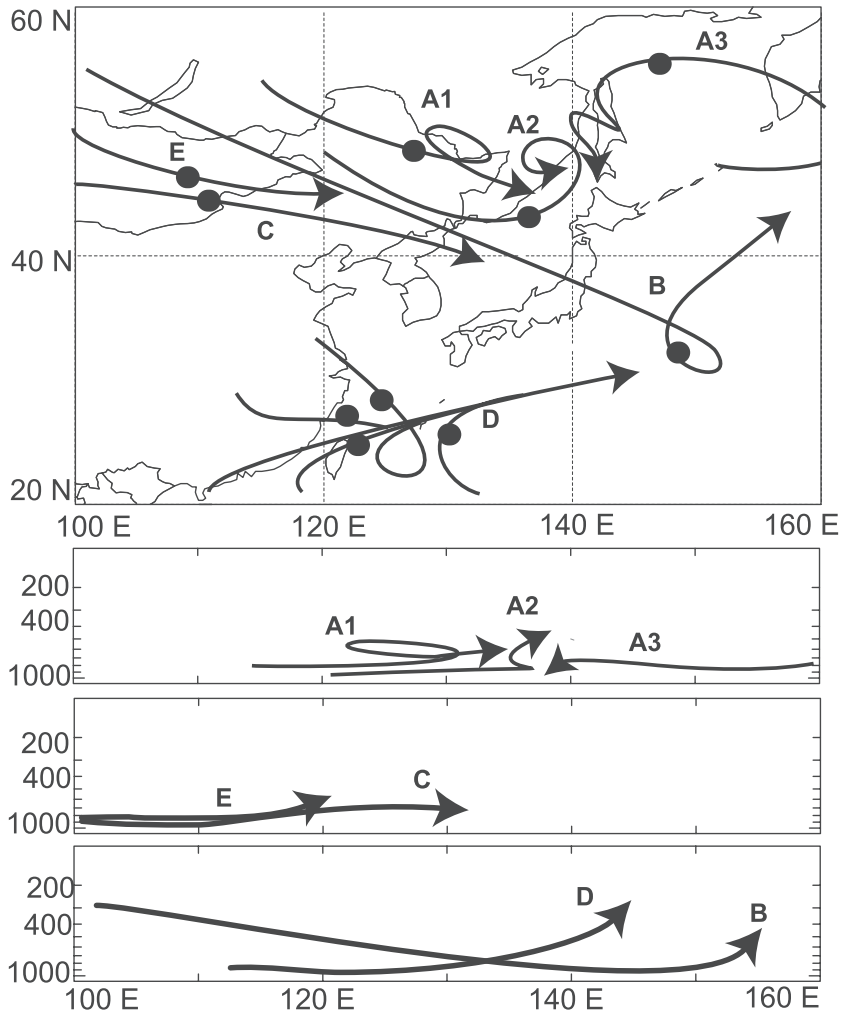

Figure 5. Schematic of 3.5 day paths of the rising airstreams arriving at 0300 UTC 21 March 2001 and having a 36-hour boundary layer history. Filled circles indicate the positions of the airstreams 36 hours back.

[29] Airstreams $\mathrm{A} 1$ and $\mathrm{A} 2$ are related to $\mathrm{C} 1$ prior to its merger with $\mathrm{C} 2$. A1 ascends near the cyclone center from the west (Figure 5), followed by cyclonic circulation around the low at midaltitudes. A2's path is slightly different, originating southeast of A1 in the boundary layer over the northern Sea of Japan and adjacent coastal areas. Its path is ahead of the cold front and like Al shows a cyclonic tendency.

[30] Although the paths of A1 and A2 are similar, their moisture characteristics are quite different. Fields of equivalent potential temperature $\left(\theta_{\mathrm{e}}\right)$ at 600 and $700 \mathrm{hPa}$ (Figure 6) reveal that $\mathrm{A} 1$ is located in a dry region, with $\theta_{\mathrm{e}}$ ranging from 275 to $285 \mathrm{~K}$. Conversely, A2 is located in a northward extending moist region, with $\theta_{\mathrm{e}}$ ranging from 285 to $295 \mathrm{~K}$.

[31] One should note that the paths and moisture properties of A1 and A2 do not correspond to airstreams in the classic cyclone models [e.g., Carlson, 1980]. For example, the classic model does not account for dry, ascending airflow near the cyclone center (A1) although it has been described more recently [e.g., Durran and Weber, 1988; Mass and Schultz, 1993]. Also, although A2 is similar to a warm conveyor belt in its initial direction of flow and its proximity to the cold front, its limited vertical depth, horizontal extent, and cyclonic curvature are quite different from a classic WCB. On the other hand, the path of A2 is comparable to the modified W2 vortex-type airstream of Bader et al. [1995] and Martin [1999], peeling away from the main WCB at middle levels and wrapping cyclonically around the surface low-pressure center.
[32] The path of airstream A3 (Figure 5) is similar to a cold conveyor belt (CCB) [Carlson, 1980]. A3 is evident only at altitudes of $\sim 700 \mathrm{hPa}$ and below, approaching $\mathrm{C} 1 / \mathrm{C} 2$ from the northeast. Although early cyclone models depicted the $\mathrm{CCB}$ as extending to the middle troposphere and undergoing anticyclonic curvature, most recent studies have yielded differing results [e.g., Mass and Schultz, 1993]. They suggest that the bulk of a CCB actually remains at low levels and travels in a cyclonic path around the cyclone center [Schultz, 2001], similar to A3.

[33] In total, region A represents a complex juxtaposition of former boundary layer air that is transported aloft by three airstreams having different histories and likely having different chemical signatures. While some characteristics of these airstreams are similar to those of previous studies,

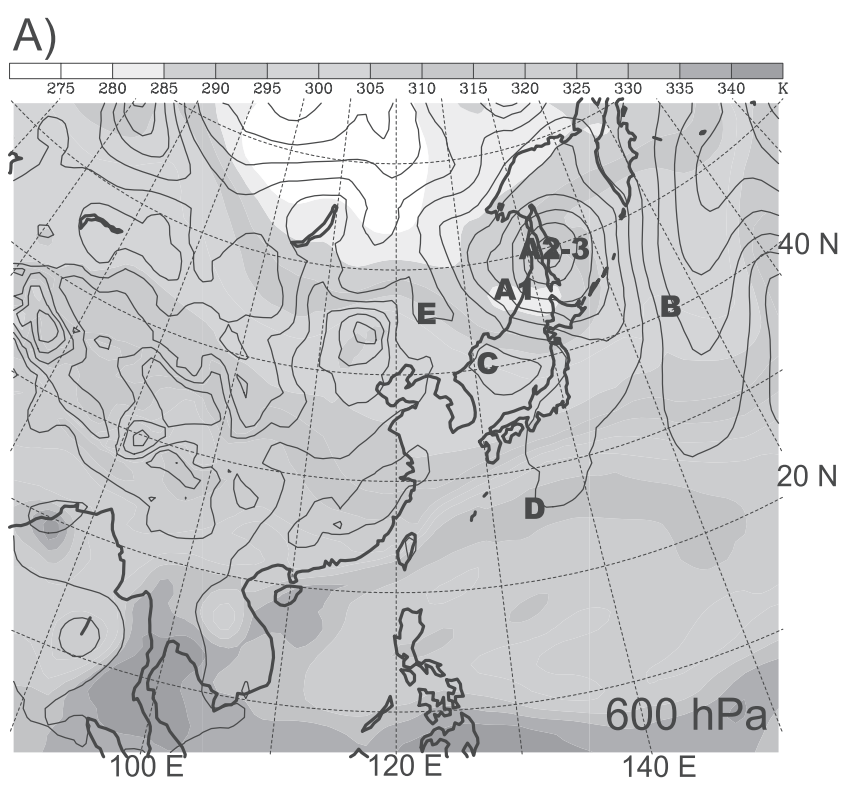

B)

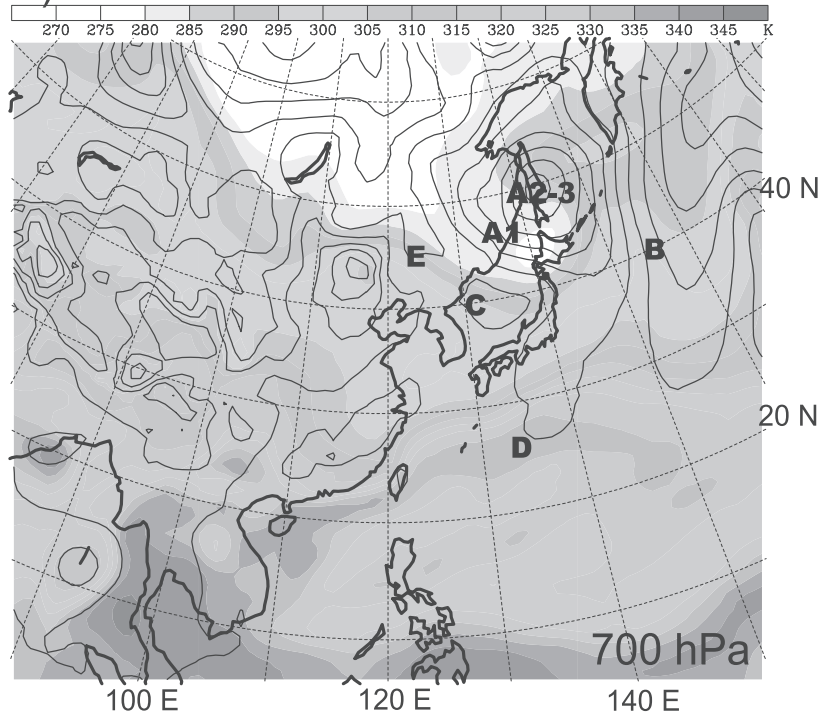

Figure 6. MM5 equivalent potential temperature (K, shaded) and sea level pressure (hPa) forecast valid at 0300 UTC 21 March for (a) $600 \mathrm{hPa}$ and (b) $700 \mathrm{hPa}$. Positions of the seven rising airstreams in Figure 6 are indicated. 
they do not fit any single conceptual model of airflow within midlatitude cyclones. The most notable differences concern depths of the flows. Specifically, all three airstreams are confined to the lower and middle troposphere $(\sim 600 \mathrm{hPa})$. Clearly, the complex interaction and subsequent merging of $\mathrm{C} 1$ and $\mathrm{C} 2$ lead to important transport pathways from the boundary layer to the free troposphere that are not described by simple conceptual models.

\subsection{Regions $\mathrm{C}$ and E: Post Cold Frontal Ascent}

[34] Regions C and E (Figure 4a), in the northwestern portion of the modeling domain occur behind the cold front in an area typically associated with large-scale subsidence. Each region consists of a shallow post-cold frontal airstream (Figure 5) that draws dry, boundary layer air from the Mongolian Plateau and, previously, the Siberian Plateau. Owing to the high terrain over which they originate and the chosen definition of the boundary layer $(p>850 \mathrm{hPa})$, these airstreams need only modest vertical ascent to reach the free troposphere. In fact, even in the absence of vertical air motions, horizontal advection from high plateaus can transfer boundary layer air to the free troposphere over lower lying downstream areas.

[35] Airstreams $\mathrm{C}$ and $\mathrm{E}$ both flow across high plateaus. Close examination of their individual trajectories (not shown) indicates ascent due to a mountain/valley wind circulation near the edge of the Mongolian plateau. Thus the vented boundary layer air comprising regions $\mathrm{C}$ and $\mathrm{E}$ results from the effects of a topographic circulation on post cold frontal air associated with $\mathrm{C} 1$.

[36] The above-mentioned upward transport associated with regions $\mathrm{A}, \mathrm{C}$, and $\mathrm{E}$ of cyclones $\mathrm{C} 1 / \mathrm{C} 2$ has important chemical consequences. With the exception of $\mathrm{A} 3$, each airstream has a boundary layer history near known sources of anthropogenic emissions and/or dust and mineral aerosols [Streets et al., 2003]. Therefore pollution could be transported into the lower to middle troposphere, from even these relatively shallow airstreams associated with the midlatitude cyclones.

\subsection{Regions B and D: Aircraft Sampling of a Polluted Prefrontal Airstream}

[37] Sharp gradients in atmospheric chemistry have been documented across frontal boundaries, with differing chemical signatures within the airstreams on either side [e.g., Bethan et al., 1998]. Furthermore, cold fronts are known to be areas where air masses are transported and mixed [e.g., Esler and Haynes, 2003]. The DC-8 and P-3B flights on 21 March examined chemical transport near the cold front extending northeast to southwest off the east coast of Japan, near regions $\mathrm{B}$ and $\mathrm{D}$ of previously boundary layer air (Figure 4). Both flights originated and terminated at Yokota Air Base, Japan, but were conducted in different locations. The P3-B sampled the northern section of the front, near the parent low-pressure center, crossing from the cold side of the front into the warm air to the east and then back. The DC8 also made two frontal crossings but along its southern and western portions. Both DC-8 crossings were well away from the parent cyclone's center, in a region where the front was stalling and southeast of a weak, developing frontal wave.

[38] Concentrations of the anthropogenic tracers carbon monoxide $(\mathrm{CO})$, ethyne $\left(\mathrm{C}_{2} \mathrm{H}_{2}\right)$, and propane $\left(\mathrm{C}_{3} \mathrm{H}_{8}\right)$ are

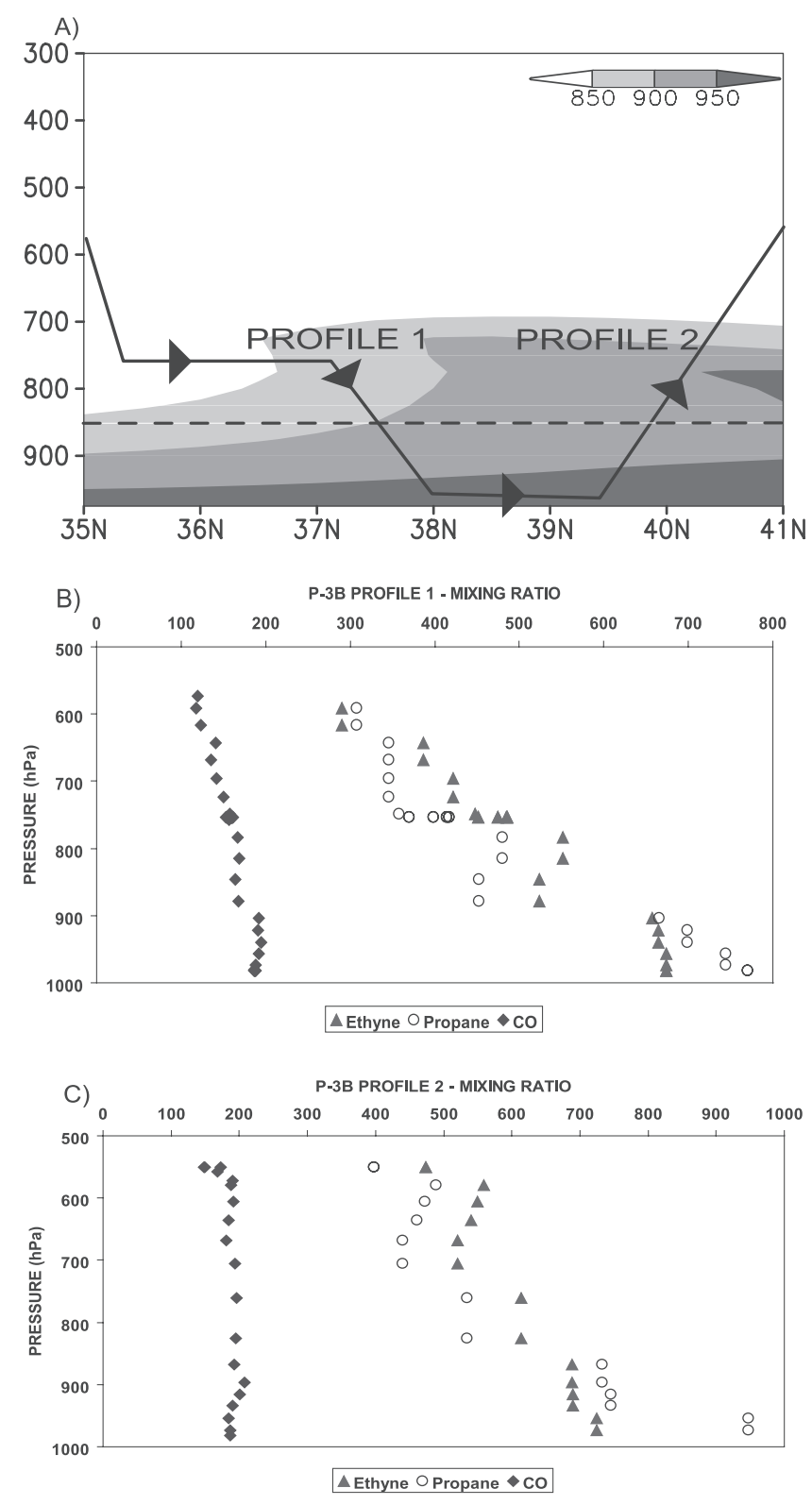

Figure 7. (a) Cross section of RDF 36-hour boundary layer air (hPa) at 0300 UTC 21 March 2001 along P3B vertical profiles 1 and 2 (RDF feature B in Figure 5). (b) Mixing ratios of ethyne (pptv), propane (pptv), and $\mathrm{CO}$ (ppbv) along P-3B profile 1. (c) As in Figure 7b but for P-3B profile 2.

examined with respect to airstreams B and D. CO's lifetime varies based on latitude and altitude, but is on the order of months. Ethyne and propane are shorter-lived species with lower tropospheric midlatitude lifetimes on the order of $1-$ 2 weeks [Streets et al., 2003].

[39] The vertical cross section of RDF 36-hour maximum pressure in Figure 7a corresponds to the P-3B's south-tonorth oriented flight leg along $155^{\circ} \mathrm{E}$ (Figure 4). The leg consists of vertical profiles at both ends and a boundary layer run in between. Both profiles traverse the western edge of RDF feature B (Figure 4), the result of an ascending southwest-to-northeast oriented airstream (Figure 5) along 
and just east of the cold front. The airstream is relatively shallow, with transport from the oceanic boundary layer extending to $\sim 600 \mathrm{hPa}$ east of the flight path and to $\sim 700 \mathrm{hPa}$ along the flight track itself (Figures 4 and 7).

[40] Oceanic boundary layer air typically is considered to be clean compared to continental boundary layer air, and it has been shown to be a source of relatively small chemical concentrations in the upper troposphere [Grant et al., 2000]. However, the chemical measurements during these P-3B profiles (Figures $7 b-7 c$ ) indicate an anthropogenic signature in the RDF boundary layer air. Profile 1 (Figure $7 \mathrm{~b}$ ) shows a distinct layer of enhanced hydrocarbon $(\sim 450-$ $550 \mathrm{pptv})$ and $\mathrm{CO}(\sim 165 \mathrm{ppbv})$ mixing ratios between 750 and $875 \mathrm{hPa}$, with even greater values within the boundary layer but smaller values above $750 \mathrm{hPa}$. It is significant that the chemical enhancement begins along the $750 \mathrm{hPa}$ flight leg as the aircraft enters the RDF feature (Figure 7a), indicating the quality of the MM5-derived RDF products.

[41] Enhancements of hydrocarbons and CO ( 525$625 \mathrm{pptv}, \sim 200 \mathrm{ppbv}$, respectively) are greater in profile 2 (Figure $7 \mathrm{c}$ ) than in profile 1 and extend through a greater depth of the troposphere. This chemical enhancement in profile 2 corresponds to an area where the RDF boundary layer signature extends to higher altitudes and exhibits greater maximum 36-hour pressures than in profile 1 (Figure 7a). That is, the RDF feature along profile 2 consists of air that has traveled closer to the surface before being lofted.

[42] As mentioned earlier, ascending flows ahead of surface cold fronts (e.g., classical WCBs) often are assumed to be "clean" when their origins are over water. However, in this case, the presence of anthropogenic pollution lofted from the marine boundary layer can be explained by 3.5 day back trajectories. These trajectories, calculated at 1-min intervals from flight positions during profiles 1 and 2 (Figures $8 \mathrm{a}-8 \mathrm{~b}$ ), reveal important characteristics about the history of the air. In the upper, unpolluted levels of both profiles (U in Figure 8) the trajectories subside slightly from high altitudes as they approach the flight region. However, the air remains at altitudes above the boundary layer throughout its history and does not tap the surface-based pollution, consistent with the relatively small chemical values at these flight levels.

[43] Air within the polluted layer has a much different history (P in Figure 8). It descends from midaltitudes while traveling rapidly southeastward from near Lake Baikal $\left(\sim 55^{\circ} \mathrm{N}, 110^{\circ} \mathrm{E}\right)$. This is followed by transport within the boundary layer over Japan and eastern Asia. As the trajectories pass offshore and approach flight level from the south/southeast, they ascend out of the boundary layer in a looping pattern. Thus the air behind the cold front travels offshore and eventually becomes part of the ascending airstream ahead of the next eastward advancing cold front. This is an interesting finding that shows the rapid interactions that occur between successive wave cyclones that pass near Japan every several days during the cool season. It also illustrates the potential for pollution transport by prefrontal oceanic airstreams that typically are thought to be clean. To our knowledge, this type of interaction between adjacent cyclones has not been previously described in the literature. However, it is reminiscent of return flow in the central and southern United States [e.g., Lewis et al., 1989; Lewis and Crisp, 1992].
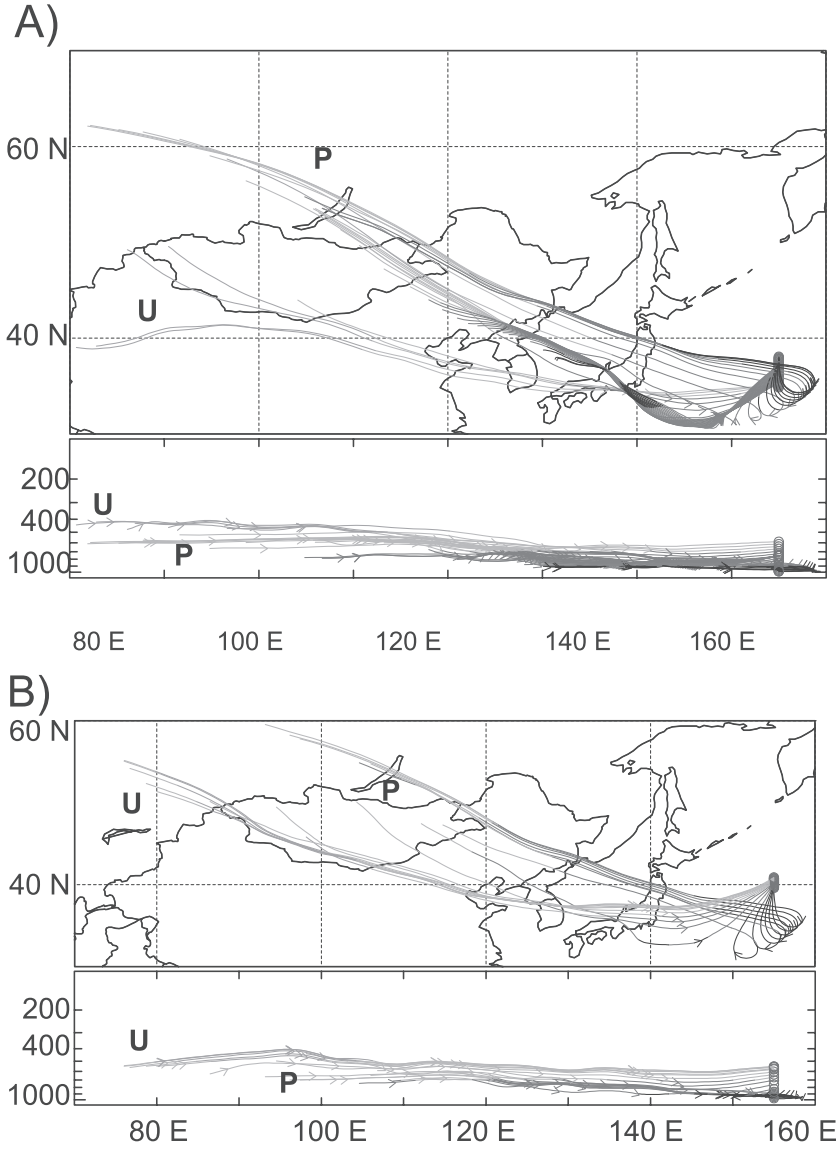

Figure 8. The 3.5-day backward trajectories from (a) P-3B profile 1 and (b) profile 2 . Trajectories arrive at 0300 UTC 21 March 2001 at RDF feature B. U and P denote unpolluted and polluted airstreams, respectively.

[44] Although airstream B occurs ahead of an approaching cold front, its shallow depth $(600 \mathrm{hPa}$ and below, Figures 4 and 5) contrasts with most descriptions of the WCB [e.g., Carlson, 1980; Wernli, 1997; Wernli and Davies, 1997; Stohl, 2001]. Nonetheless, the short time span over which the air moves offshore and then ascends ( $\sim 2$ days in Figure 8 ) has important chemical implications. Specifically, polluted post cold frontal air may have little time to be cleansed photochemically or by scavenging before being lofted to higher altitudes and subsequently transported by a successive cyclone. Therefore precold frontal ascending airstreams are not necessarily clean by virtue of their maritime boundary layer source alone. Rather, their relative cleanliness also is affected greatly by their long-range transport history.

[45] Considering the final RDF region on 21 March, region D (Figure 4) is the most expansive and deepest of the previously boundary layer airstreams, extending to above $400 \mathrm{hPa}$. It is located near the southwestern limit of the cold front associated with cyclones $\mathrm{C} 1 / \mathrm{C} 2$, and southwest of the weak, developing frontal wave. Trajectories comprising airstream D (Figure 5) illustrate its geographic extent and wide boundary layer source region. The ascending airstream results from large-scale convergence of air near the stalling frontal zone. Thus it has several tributaries, 

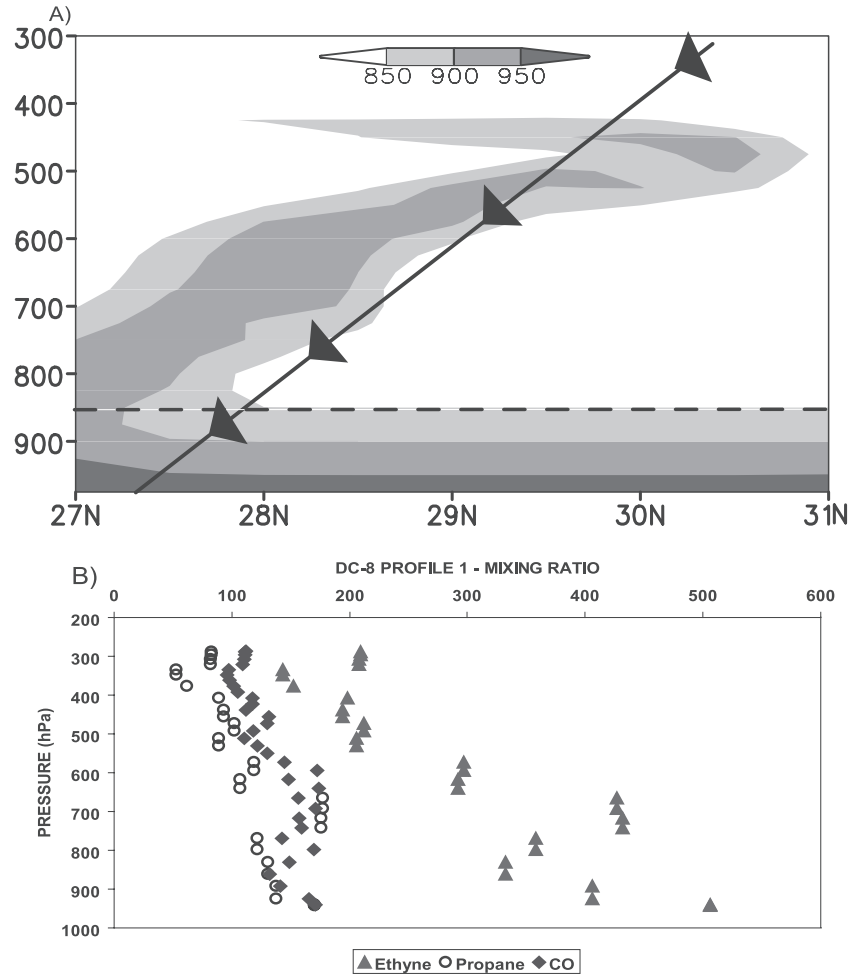

Figure 9. (a) Cross section of RDF 36-hour boundary layer air $(\mathrm{hPa})$ at 0300 UTC 21 March 2001 along DC-8 profile 1 (RDF feature D in Figure 5). (b) Mixing ratios of ethyne (pptv), propane (pptv), and CO (ppbv) along DC-8 profile 1.

drawing air from both the continental boundary layer of eastern Asia and the maritime boundary layer east of the continent.

[46] The DC-8 crossed RDF feature D twice (Figure 4), once heading southwest from Yokota $\left(\sim 28^{\circ} \mathrm{N}, 137^{\circ} \mathrm{E}\right)$ and again heading northwest near $25^{\circ} \mathrm{N}, 125^{\circ} \mathrm{E}$. The vertical extent of the RDF boundary layer air during the first crossing (profile 1) is illustrated in a cross section along the descending flight path (Figure 9a). The aircraft traverses an upward extending tongue of the lifted boundary layer feature between $\sim 400$ and $600 \mathrm{hPa}$ and then parallels the edge of the signature as it descends closer toward the surface.

[47] Values of hydrocarbons and CO (Figure 9b) during the descent are relatively small above $\sim 600 \mathrm{hPa}$, even within the previously boundary layer air. At lower altitudes, however, the hydrocarbons are enhanced between 600 and $750 \mathrm{hPa}$, while $\mathrm{CO}$ exhibits many small oscillations between $600 \mathrm{hPa}$ and the surface. This chemical distribution apparently is due to the proximity of the aircraft to the edge of the RDF feature. That is, as the aircraft skirts the periphery of the lifted air, it likely samples a mixture of boundary layer and tropospheric background air.

[48] One should note that upper portions of the air lifted from the boundary layer ( $\sim 400-600 \mathrm{hPa}$, Figure 9b) exhibit smaller chemical values than observed along its edge at middle levels $(\sim 600-850 \mathrm{hPa})$. The 3.5 day backward trajectories from profile 1 (Figure 10) indicate that air comprising the upper (U) portion of RDF feature D originates over the subtropical oceanic boundary layer, typically a clean source region. This air travels northwestward and then northeastward at low altitudes before rising near the cold front. On the other hand, air within the middle portion of the lifted layer (P) travels almost due east from the continental boundary layer over highly populated and industrialized regions of eastern China before ascending to flight level. Thus the chemical distribution within profile 1 of region D (Figure 9a) results from air having different origins and therefore different chemical compositions.

[49] Conditions at the DC-8's second crossing of region $\mathrm{D}$ (profile 2) are quite different from those at profile 1. Profile 2 occurs near the westernmost portion of region D (Figure 4), near the surface cold front. It consists of a flight leg at $644 \mathrm{hPa}$ followed by descent through the frontal surface near $27.5^{\circ} \mathrm{N}$ (Figure 11). The DC-8 encounters RDF boundary layer air for nearly the entire $644 \mathrm{hPa}$ flight leg. The aircraft then briefly exits the boundary layer influenced air near $27^{\circ} \mathrm{N}$ before beginning its descent. A second encounter occurs through a nose of the RDF feature $(\sim 725-775 \mathrm{hPa})$. At this point the DC-8 leaves the RDF air until reaching the boundary layer near $850 \mathrm{hPa}$.

[50] Figure $11 \mathrm{~b}$ indicates variable mixing ratios of $\mathrm{CO}$ and hydrocarbons along the $644 \mathrm{hPa}$ flight leg. Although the chemical plot does not show the horizontal location of the aircraft with respect to the chemical values at this level, the trend is increasing chemical concentrations from south to north. Mixing ratios decrease near $26.5^{\circ} \mathrm{N}$, corresponding to the brief exit of the aircraft from the boundary layer influenced air, but they again increase while descending through the nose of the RDF feature from 700 to $775 \mathrm{hPa}$. The overall trend is greater chemical concentrations in the northern section of the RDF feature.

[51] Backward trajectories from the DC-8 flight track (not shown) are very similar to those at the same altitudes in profile 1 (Figure 10). That is, air sampled

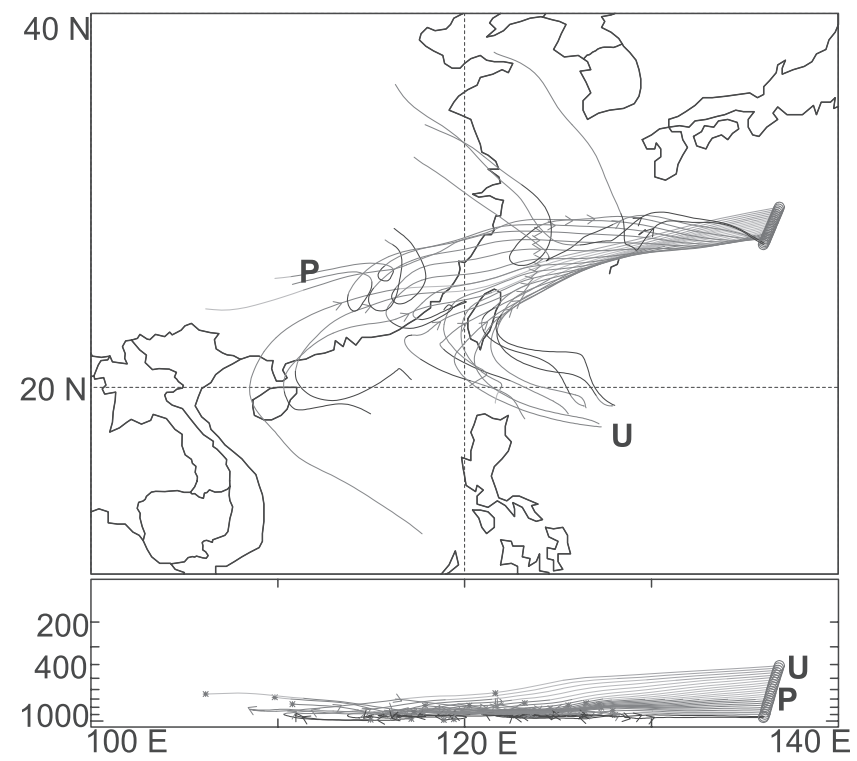

Figure 10. The 3.5 day backward trajectories from DC-8 profile 1. Trajectories arrive at 0300 UTC 21 March 2001 at RDF feature D. U and $\mathrm{P}$ denote unpolluted and polluted airstreams, respectively. 
A)
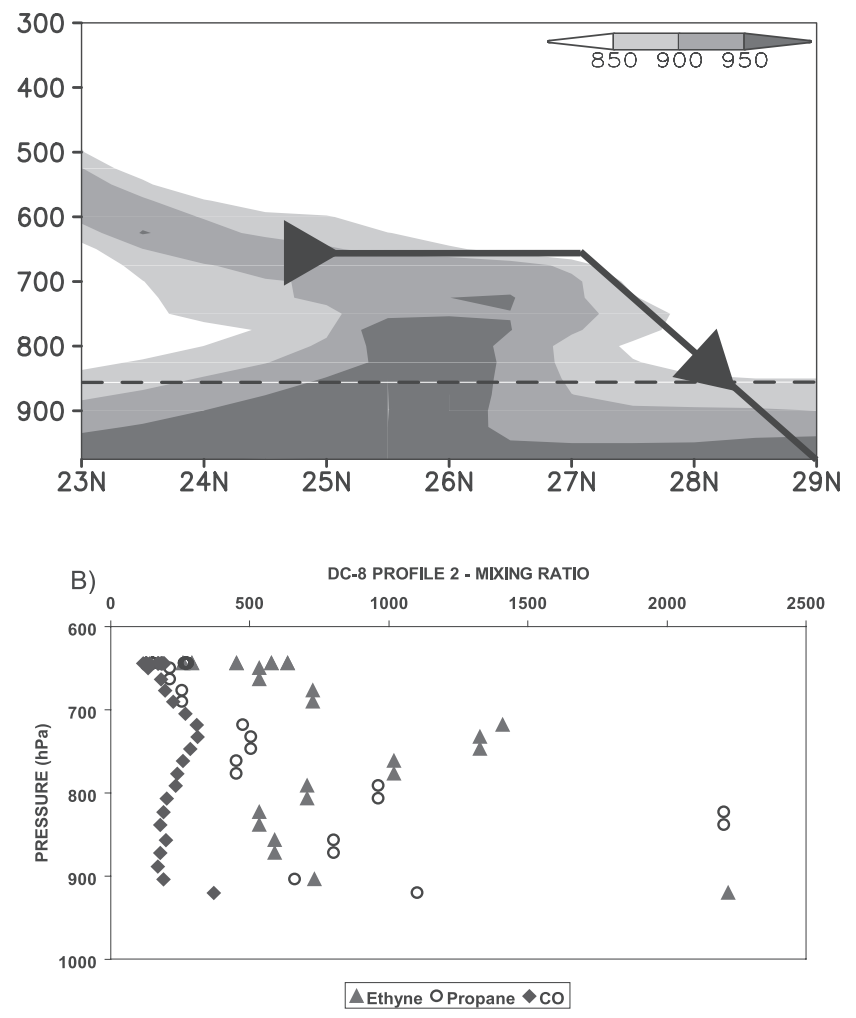

Figure 11. (a) Cross section of RDF 36-hour boundary layer air (hPa) at 0300 UTC 21 March 2001 along DC-8 profile 2 (RDF feature D in Figure 5). (b) Mixing ratios of ethyne (pptv), propane (pptv), and CO (ppbv) along DC-8 profile 2 .

by the DC-8 exhibits multiple influences during the previous 36-hours. Air along the relatively clean southern portion of the profile arrives at the flight path from subtropical oceanic regions, whereas air arriving at the middle and northern portions of the flight track has continental origins. However, due to the proximity of the $\mathrm{DC}-8$ to the coast compared to profile 1 , even air originating over the ocean travels within the continental boundary layer before ascending at the front, thereby producing the larger chemical mixing ratios. Once again, the RDF product resolves the previous boundary layer air, attesting to its effectiveness in chemical transport applications.

\section{4 April 2001 Cyclones: P-3B Flight 20 4.1. Synoptic Environment}

[52] The case of 4 April 2001 contrasts with the complex transport patterns of 21 March. The cyclones on this day are comprised of airstreams from the boundary layer that resemble the simple configurations of conceptual models, although some notable differences still exist. The MM5 4-day forecast of sea level pressure (Figure 12) shows two cyclones on 4 April. One was occluded over the Bering Sea (L), and a mature system was north of Japan (C). Cyclone C's evolution did not involve the complex merger with another system that was observed during the 21 March case (Figure 3). Cold fronts from both cyclones extend southwestward, with ascending airstreams located near the frontal boundaries.

\subsection{Region A: Transport Near an Aged Front}

[53] Three major areas of formerly boundary layer air are revealed by the 36 -hour $\mathrm{RDF}$ procedure $(\mathrm{A}, \mathrm{B}$, and $\mathrm{C}$ in Figure 13). Feature A, oriented southwest to northeast in the eastern part of the domain, is associated with the decaying frontal boundary that is between the occluded cyclone over the Bering Sea and the strong anticyclone farther east (near $35^{\circ} \mathrm{N}, 145^{\circ} \mathrm{W}$ ) (Figure $12 \mathrm{~d}$ ). The previously boundary layer air in $\mathrm{A}$ is relatively shallow, confined to below $\sim 600 \mathrm{hPa}$.

[54] Backward trajectories comprising A exhibit two distinct transport paths over the western Pacific, one from the southwest (A1) and the other from the southeast (A2) (Figure 14). The P-3B penetrated A1 near $700 \mathrm{hPa}$ while descending to Midway Island (Figure 15a). Values of CO and hydrocarbons during this descent (profile 1) confirm its aged character (Figure 15b). Mixing ratios are small from above the boundary layer to $\sim 600 \mathrm{hPa}$, including the portion of RDF boundary layer air $(\sim 700-850 \mathrm{hPa})$. CO ranges from $\sim 100$ to $120 \mathrm{ppbv}$ in the RDF portion of the profile, while ethyne is $\sim 150-175 \mathrm{pptv}$, and propane varies from $\sim 70$ to $\sim 120 \mathrm{pptv}$. These values are comparable to those in the upper portions of region B during the previous case (Figure 9). That area also was shown to have an oceanic boundary layer influence.

[55] Hydrocarbons and $\mathrm{CO}$ have different lifetimes, with CO's life being months compared with only weeks for the two hydrocarbons. Thus smaller ratios of hydrocarbons to $\mathrm{CO}$ indicate air that is longer removed from its pollution source. Ratios of ethyne to CO within the RDF air are $\sim 1.5$. Similar ratios were observed in the unpolluted portion of region B on 21 March (Figure 9), while ratios ranged from $\sim 2.5$ to 4.0 within polluted portions of that earlier profile. Thus, both chemical and meteorological data indicate that the boundary layer air comprising region $\mathrm{A}$ is relatively aged and clean.

[56] The northern portion of region A extends well into the midlatitudes (Figure 13). This suggests that occluded cyclones and their aging fronts that traverse the North Pacific can be effective mechanisms for transporting relatively clean marine boundary layer air into the midlatitude lower free troposphere. An important chemical consequence of this vertical transport to northern latitudes is that it can dilute polluted air originating over Asia. That is, as cyclones travel eastward across the North Pacific, their fronts act as lifting mechanisms, drawing air from the progressively cleaner boundary layer toward the east. This air then can mix with the more polluted air lifted by upstream cyclones closer to the Asian continent (C. Mari et al., Evolution of Asian pollution over the Pacific Ocean: The effect of clean warm conveyor belts, submitted to Journal of Geophysical Research, 2003).

\subsection{Region C: Recirculation}

[57] RDF feature $\mathrm{C}$ is located southeast of Japan (Figure 13). Trajectories comprising C (Figure 14) show that the formerly boundary layer air has a wide range of paths that originate over the central coast of Asia and adjacent waters. Individual trajectories (not shown) reveal an expansive area of recirculating air with characteristics similar to region $\mathrm{D}$ in 
A)

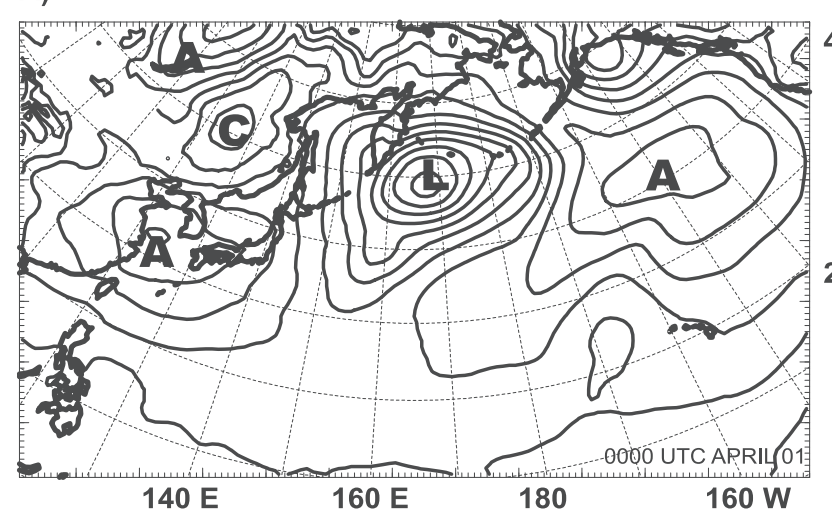

B)

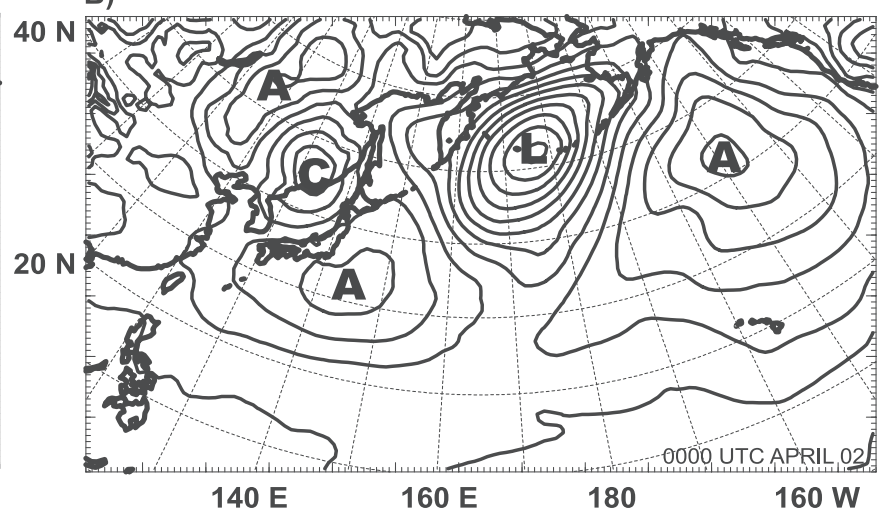

C)

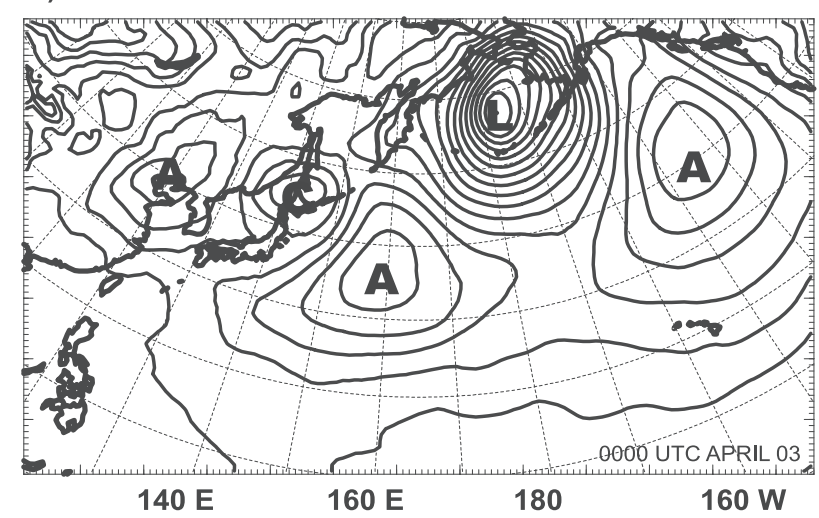

D)

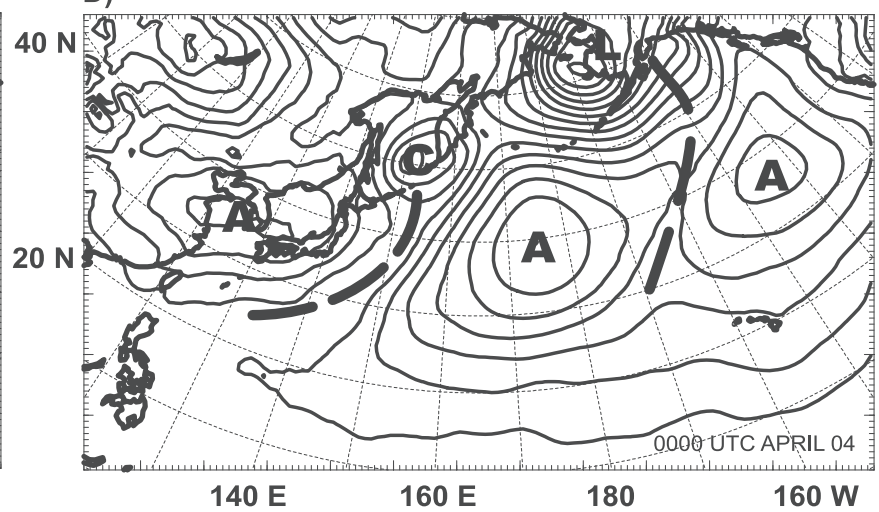

Figure 12. MM5 sea level pressure forecast for (a) 0000 UTC 1 April (F + 48), (b) 0000 UTC 2 April $(F+72)$, (c) 0000 UTC 3 April $(F+96)$, and (d) 0000 UTC 4 April $(F+120)$. C indicates the position of the cyclone center. $\mathrm{L}$ and $\mathrm{A}$ indicate positions of other low-pressure and anticyclone centers. The positions of cold fronts on April 4 are indicated by dashed curves.

the previous section (Figure 5). Both regions contain air that has both continental and maritime boundary layer histories, with some trajectories extending above $400 \mathrm{hPa}$. This region of boundary layer influence appears to result from the same process responsible for region D on 21 March (Figure 5). That is, the southernmost extent of the cold front acts as a boundary for the large-scale convergence of air having both clean and polluted characteristics.

\subsection{Region B: Multiple Modes of Transport}

[58] RDF signature B (Figure 13) appears consistent with classic [e.g., Carlson, 1980] and modified [e.g., Bader et al., 1995; Cooper et al., 2001] cyclone models. This extensive band of lifted boundary layer air stretches southwest to northeast along and east of the cold front, with portions extending above $400 \mathrm{hPa}$. The band diverges at its northernmost extent, with one arm wrapping cyclonically around the surface low-pressure feature, similar to the locations of airstreams described by Mass and Schultz [1993], Bader et al. [1995], and Martin [1999]. A second branch peels off in an anticyclonic fashion toward the east, comparable to the upper-level position of Carlson's [1980] WCB.

[59] RDF signature $B$ is the sum of three separate transport modes (Figure 14). Streams B1-B3 have 36-hour boundary layer origins ranging from Japan to the waters off the eastern Japanese coast. B1, the easternmost portion of the rising airstream, forms the anticyclonic arm of the RDF feature (Figure 13). It is the deepest of the three flows, descending from altitudes above $500 \mathrm{hPa}$ before arriving in the boundary layer offshore of Japan. Once in the boundary layer, its path indicates the influence of high pressure, looping as it ascends in advance of the approaching cold front. This looping pattern prior to ascent is similar to precold frontal airstream $\mathrm{B}$ in the previous case (Figures 5 and 8). However, there is an important difference between the two cases. Region B on 21 March had a continental boundary layer history beyond 36 hours, whereas B1 of the current case does not reach the boundary layer until well offshore of Japan (Figure 14). Thus even though the two airstreams have similar horizontal paths, their different locations within the boundary layer suggest likely contrasts in pollution signatures. Specifically, since B1 has no boundary layer history over land, it likely is relatively clean.

[60] B2's trajectories are quite different from those of B1 (Figure 14). They generally travel southeast within the boundary layer near western China, Korea, and southern Japan before ascending toward the northeast and paralleling B1. B2 does not extend into either of the northernmost RDF arm features but comprises the main southwest-northeast 

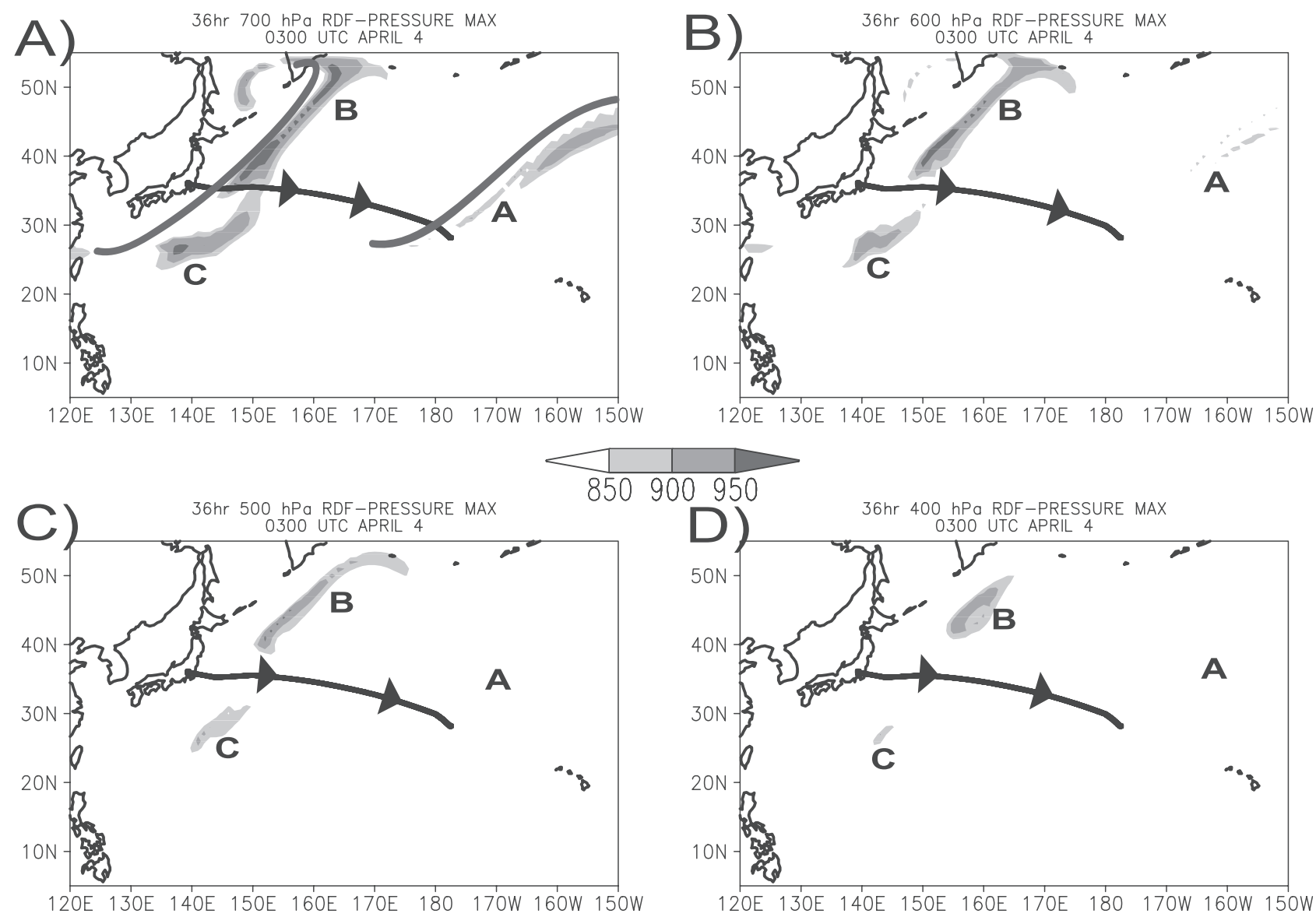

Figure 13. Reverse domain filling (RDF) of 36-hour maximum pressure (hPa) at 0300 UTC 4 April 2001 for (a) $700 \mathrm{hPa}$, (b) $600 \mathrm{hPa}$, (c) $500 \mathrm{hPa}$, and (d) $400 \mathrm{hPa}$. Shaded regions indicate air with a boundary layer history. Flight track (arrows) and surface cold front positions (curved lines) are indicated.

oriented band. Owing to its history in the continental boundary layer, B2 likely exhibits a greater pollution influence than B1.

[61] Segment B3 (Figure 14) is associated with the RDF cyclonic extension that is evident at $600 \mathrm{hPa}$ and below (Figure 13). This component of the overall airstream travels southeast at altitudes just above the boundary layer over Korea before turning northeast and ascending. However, as it travels over Japan, it descends into the boundary layer where it probably is influenced by anthropogenic emissions. Therefore this cyclonic extension of the RDF feature likely exhibits pollution levels intermediate to those of B1 and B2.

[62] Summarizing, RDF signature B exhibits a classic structure with respect to the location of lifted boundary layer air. However, close examination indicates three separate transport components. Each exhibits a different altitude history that likely leads to differences in chemical composition. These hypotheses regarding composition are explored in the following section.

\subsection{Region B: Aircraft Sampling of a Clean Prefrontal Airstream}

[63] The P-3B's flight through lifted boundary layer air at region $\mathrm{B}$ near $35^{\circ} \mathrm{N}, 146-152^{\circ} \mathrm{E}$ (Figure 13) is illustrated in Figure 16. Profile 2 descends into the RDF feature at $\sim 650 \mathrm{hPa}$ and intercepts the greatest $\mathrm{RDF}$ maximum pressures $(>950 \mathrm{hPa})$ at $\sim 750 \mathrm{hPa}$. Unlike region B sam-
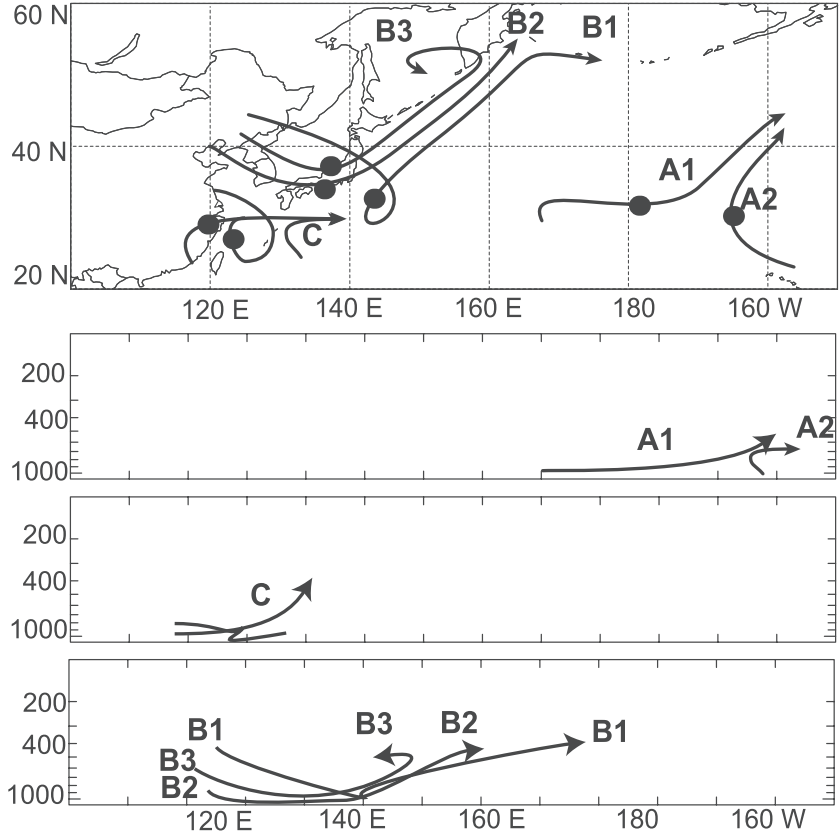

Figure 14. Schematic of 3.5 day paths of the rising airstreams arriving at 0300 UTC 4 April 2001 and having a 36-hour boundary layer history. Filled circles indicate the positions of the airstreams 36 hours back. 
A)
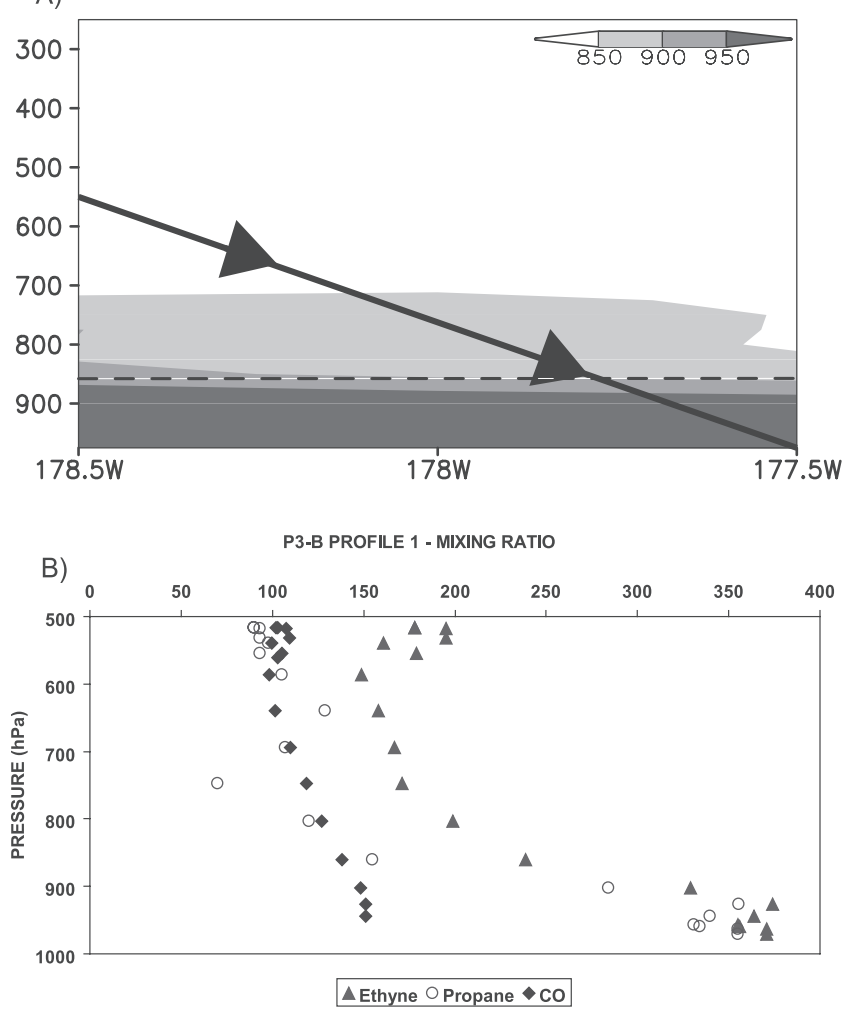

Figure 15. (a) Cross section of RDF 36-hour boundary layer air $(\mathrm{hPa})$ at $0300 \mathrm{UTC} 4$ April 2001 along P-3B profile 1 (RDF feature A1 in Figure 14). (b) Mixing ratios of ethyne (pptv), propane (pptv), and CO (ppbv) along P-3B profile 1 .

pled on 21 March (Figures $7 b-7 c$ ), current mixing ratios (Figure 16b) do not show a distinct layer that corresponds to the RDF air. Instead they gradually increase below $\sim 700$ $\mathrm{hPa}$ and spike at $\sim 800 \mathrm{hPa}$. CO ranges from $\sim 150 \mathrm{ppbv}$ near the top of the RDF layer to a maximum of $\sim 200 \mathrm{ppbv}$ at the spike. Similarly, hydrocarbon values are relatively small above $700 \mathrm{hPa}$ but become greater within the RDF layer $(\sim 650-850 \mathrm{hPa})$, exhibiting maxima of $\sim 475 \mathrm{pptv}$ (propane) and $550 \mathrm{pptv}$ (ethyne) near $800 \mathrm{hPa}$.

[64] Trajectories and corresponding $\mathrm{CO}$ mixing ratios within the elevated RDF layer of profile $2(675-850 \mathrm{hPa})$ (Figure 17) clarify the chemical signatures. Trajectories corresponding to the greatest CO mixing ratios $(183,185$, and $207 \mathrm{ppbv}$ ) have continental boundary layer histories similar to airstream B2 (Figure 14). They travel within the boundary layer near Korea and southern Japan before ascending to flight altitude. Conversely, the two trajectories associated with smaller CO mixing ratios (164, 170 ppbv) are similar to airstream B1, subsiding from the free troposphere over Japan into the marine boundary layer offshore. Consequently, they are not subject to anthropogenic emissions from Japan. Thus the western part of RDF region B (profile 2) is not a tightly bound flow but an incoherent region associated with differing transport pathways and therefore differing chemical influences.

[65] Profile 3 in region $\mathrm{B}$ ascends in a stepped fashion from the boundary layer at $35^{\circ} \mathrm{N}, 148^{\circ} \mathrm{E}$ (Figure 16a). The first level leg occurs at $\sim 840 \mathrm{hPa}$ near the top of the strong $\mathrm{RDF}$ signature. The $\mathrm{P}-3 \mathrm{~B}$ then ascends to a second level leg at $\sim 720 \mathrm{hPa}$, exiting the RDF feature near the middle of the leg. Compared to profile 2, the RDF air along profile 3 is shallower, with greatest maximum pressures confined to lower altitudes. Unlike the chemical signatures of profile 2 and region $B$ on March 21 (Figures $7 b-7 c$ ), chemical signatures in the current area suggest relatively clean formerly boundary layer air between 850 and $720 \mathrm{hPa}$, with greater pollution above and below. $\mathrm{CO}$ in the layer ranges from $\sim 150$ to $165 \mathrm{ppbv}$, while propane and ethyne exhibit median values of $\sim 350$ pptv and $\sim 270$ pptv, respectively. In

A)
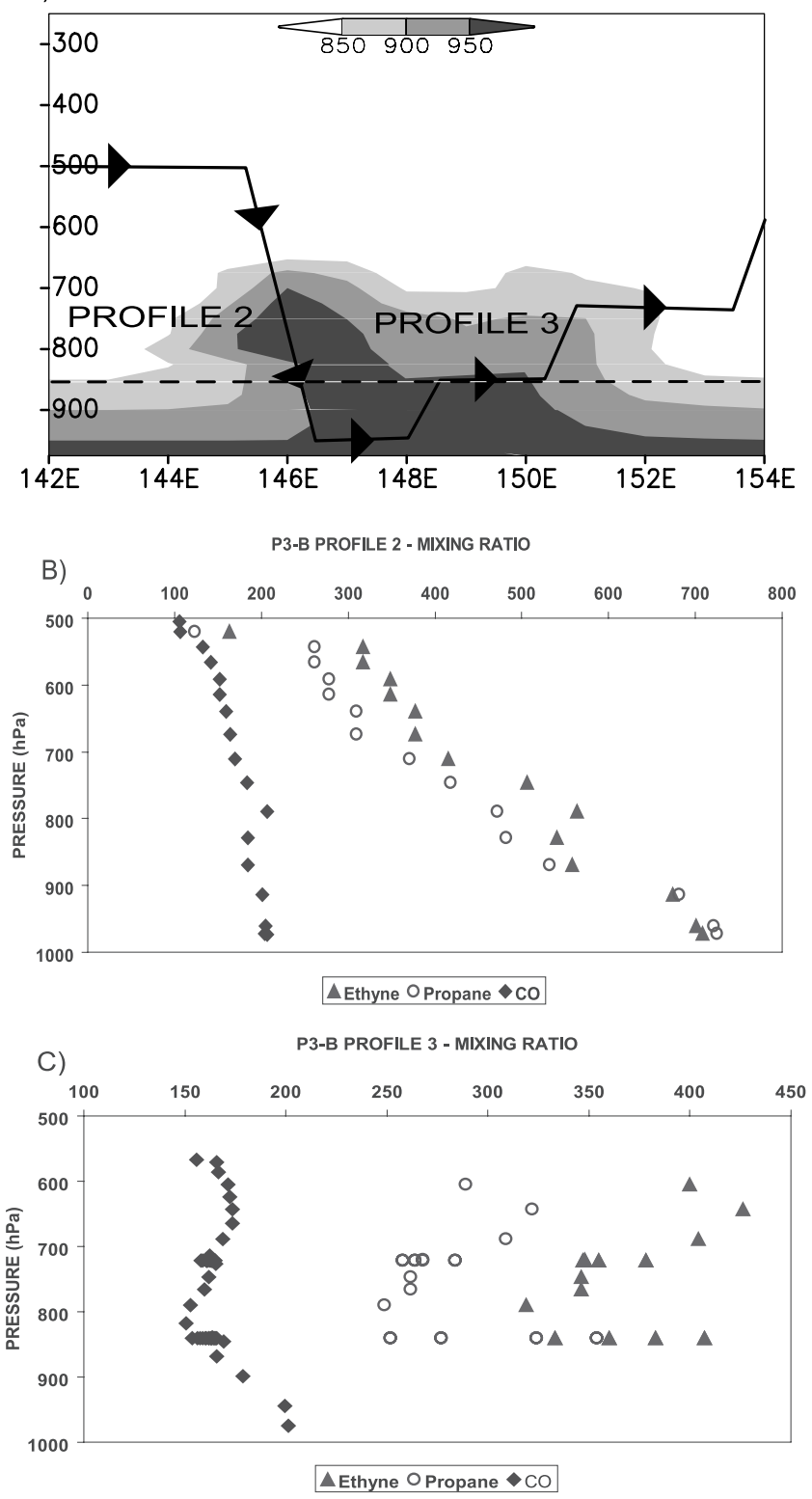

Figure 16. (a) Cross section of RDF 36-hour boundary layer air (hPa) at 0300 UTC 4 April 2001 along P3-B profiles 2 and 3 (RDF feature B in Figure 14). (b) Mixing ratios of ethyne (pptv), propane (pptv), and $\mathrm{CO}$ (ppbv) along $\mathrm{P}-3 \mathrm{~B}$ profile 2. (c) As in Figure $16 \mathrm{~b}$ but for P-3B profile 3 . 

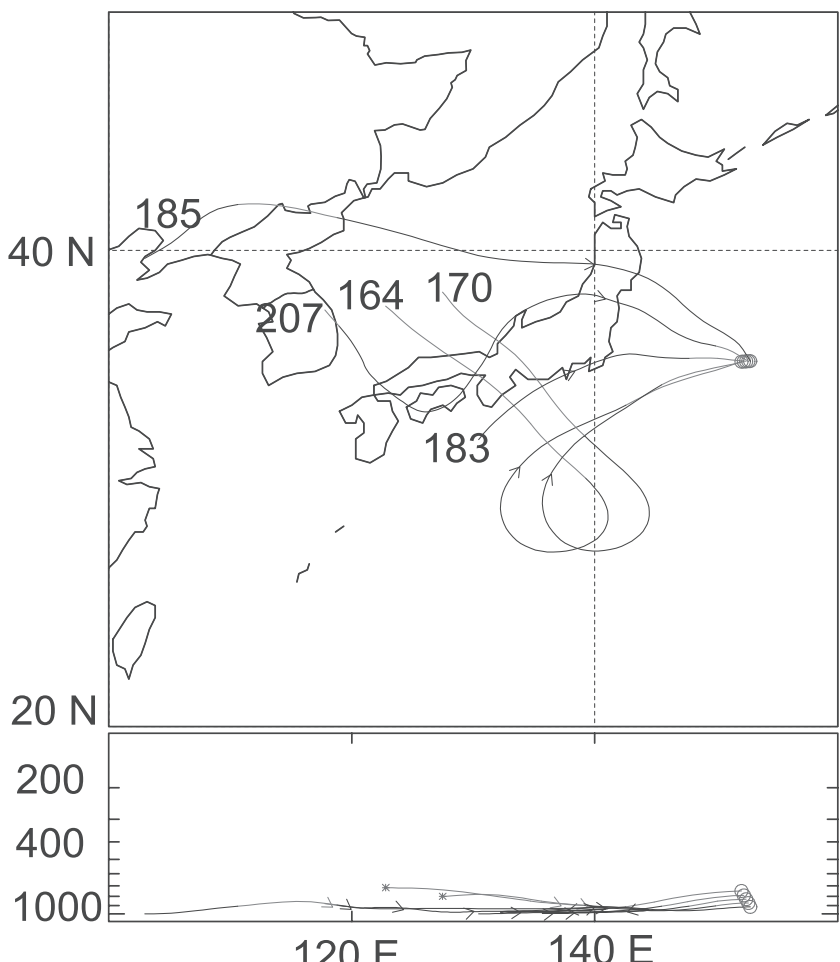

Figure 17. The 3.5-day backward trajectories and CO mixing ratios (ppbv) from $\mathrm{P}-3 \mathrm{~B}$ profile 2 . Trajectories arrive at 0300 UTC 4 April 2001 at RDF feature B.

comparison, hydrocarbon values in the polluted portions of profile 2 (Figure 16b) and in profiles $1-2$ of the P-3B's 21 March flight (Figures $7 \mathrm{~b}-7 \mathrm{c}$ ) ranged from 450 to 525 pptv (propane) and 500 to 650 pptv (ethyne). The difference in $\mathrm{CO}$ concentrations between cases is somewhat less pronounced, owing to its longer lifetime, with ranges from $\sim 150$ to $165 \mathrm{ppbv}$ in profile 3 , compared to $\sim 165-$ 200 ppbv in profile 2 and profiles $1-2$ of 21 March.

[66] The 3.5 day backward trajectories from the relatively clean 840-720 hPa layer are shown in Figure 18. Although two slightly different paths are evident, both descend from high altitudes $(<500 \mathrm{hPa})$ to the marine boundary layer offshore of Japan. Thus this air is free from continental boundary layer influence, as reflected by the relatively clean chemical signature in Figure 16.

[67] It is important to note that the chemical characteristics of the prefrontal ascending airstreams on 21 March (Figures 7 and 9) and 4 April (Figure 16) are very different even though they occur in approximately the same geographical location with respect to the Asian coast. This suggests that the altitudes of airstreams prior to their ascent near cold fronts is more important in determining pollution concentrations than is their proximity to the coast. That is, prefrontal airstreams ascending from the marine boundary layer may be either clean or polluted, depending on where the air encounters the boundary layer.

\section{Summary and Conclusions}

[68] The transport of boundary layer air to the free troposphere by cyclones has been investigated on 2 days during NASA's Transport and Chemical Evolution over the Pacific (TRACE-P) experiment. A high-resolution numerical model (MM5) was used with in situ chemical data to examine the chemical composition and transport capabilities of ascending airstreams.

[69] Hourly wind data from MM5 were used to construct 3-D grids of backward air trajectories over eastern Asia and the western Pacific. A reverse domain filling technique (RDF) utilized the gridded trajectory data to examine the quasi-Lagrangian properties of the air. Airstreams ascending from the boundary layer to the free troposphere during the previous 36-hours then were isolated.

[70] The first case focused on three cyclones occurring on 21 March 2001. These cyclones produced a complex arrangement of airstreams that transported boundary layer air to five regions in the lower to middle troposphere. Most transport from the boundary layer was associated with two cyclones that merged over the western Pacific. A large area of lifted boundary layer air was located near the center of the merged cyclone. This air was deposited at altitudes below $\sim 600 \mathrm{hPa}$ by three distinct airstreams. Two of these airstreams (A2 and A3) ascended from the moist boundary layer east of the cyclone center and wrapped cyclonically around the low-pressure center. The third (A1) was characterized by dry ascent behind the cold front, followed by cyclonic circulation.

[71] Two additional ascending airstreams ( $\mathrm{C}$ and $\mathrm{E})$ were located in the post-cold frontal air mass of the cyclone. These airstreams originated over high plateaus and were lofted to even higher altitudes when they intersected thermally induced upslope circulations near the plateaus' edges.

[72] The P-3B aircraft sampled region B that was influenced by boundary layer venting ahead of the cold front associated with the merged cyclone. This airstream was found to contain enhanced $\mathrm{CO}$ and hydrocarbons. Backward trajectories indicated that this enhancement was due to boundary layer transport over eastern Asia and Japan 2-

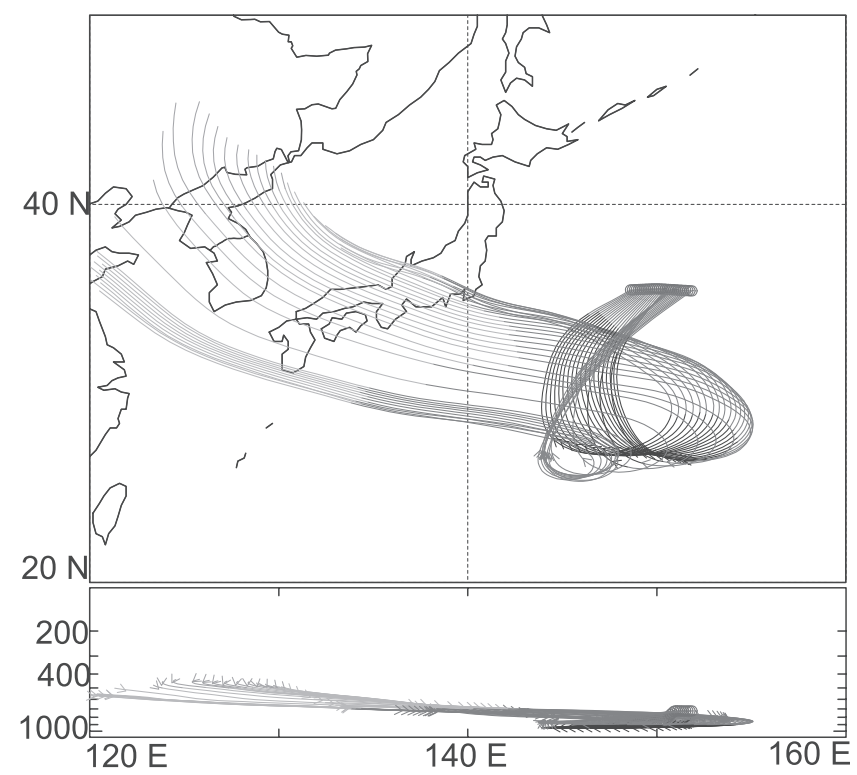

Figure 18. The 3.5-day backward trajectories from P-3B profile 3. Trajectories arrive at 0300 UTC 4 April 2001 at RDF feature $\mathrm{B}$. 
3 days prior to aircraft sampling. The airstream was a post cold-frontal flow that rapidly became the ascending prefrontal flow of the next upstream, eastward moving cyclone. This interaction between successive cyclone/anticyclone couplets is an interesting and unexpected result, and there are important chemical implications to this scenario since precold frontal airstreams ascending from the oceanic boundary layer typically are thought be clean. Current results, however, indicate that precold frontal flows exhibit highly variable evolutions and therefore are likely to be highly variable in their chemical composition and transport potential.

[73] The DC-8 twice sampled lifted boundary layer air (region D) along the southern portion of the cold front. Trajectories and chemical data confirmed that this air had multiple source regions over a wide geographic area. Clean portions of the airstream exhibited a marine boundary layer history, while polluted sections showed an influence from the continental boundary layer over eastern Asia.

[74] Some aspects of the airstreams on 21 March were similar to those from classic conceptual models and recent studies. However, the depths and altitudes of the current airstreams often differed from the models. Although the current airstreams were relatively shallow, they clearly have the potential to transport pollution into the lower and middle troposphere due to their boundary layer histories near sources of anthropogenic emissions and dust/mineral aerosols.

[75] The second case examined the transport of boundary layer air by cyclones on 4 April 2001. The P-3B aircraft intersected lifted boundary layer air (region A1) along the southern portion of a cold front during descent to Midway Island. Chemical data from the P-3B as well as backward trajectories indicated that the air was well aged. Although the airstream was shallow, it extended far to the north. Thus eastward moving cold fronts, even those associated with occluded cyclones, appear to be mechanisms for diluting polluted tropospheric air from Asia. That is, as cyclones travel eastward from Asia, their fronts act as lifting mechanisms, lofting progressively cleaner marine boundary layer air into the troposphere.

[76] In contrast to the complex transport exhibited by the cyclones in case 1 , the airstreams during case 2 more closely resembled those of conceptual models. This was due to the simpler synoptic situation that did not include cyclone mergers. The ascending airstreams were located near frontal boundaries, and several of the airstreams contained cyclonic and anticyclonic appendages that were similar to those described in the literature. However, as in case 1 , the case 2 airstreams did not display the large depths described in previous studies.

[77] The P-3B's sampling of the pre-frontal airstream near Japan (region B) occurred in a location similar to the sampling of a comparable airstream in case 1 (also denoted region B). Backward trajectories from the airstream exhibited similar histories as those in case 1, descending into the boundary layer behind a cold front before ascending northeast in advance of the next approaching front. However, the case 2 air descended from much higher altitudes and did not reach the boundary layer until offshore of Japan, away from continental pollution sources. Thus unlike the earlier case, the $\mathrm{CO}$ and hydrocarbon measurements in case 2 indicated a relatively clean airstream.
[78] Large-scale transport of pollution near wave cyclones often is described in terms of airstreams comprising simple conceptual models. The cases presented here, however, show that complex cyclone interactions in the real atmosphere can produce airstreams that differ considerably from the models describing isolated cyclones. These differences in transport may be common occurrences due to the complexity of atmospheric systems. Although the conceptual models are useful in a general sense, they only account for broad, deep flows in idealized situations. Clearly, they do not account for shallower flows that are important for venting pollution from the boundary layer into the lower and middle troposphere.

[79] Finally, the reverse domain filling technique used in this study proved to be a valuable tool for diagnosing the location of vented boundary layer air. The MM5-derived trajectories used in the RDF calculations exhibited considerable accuracy in resolving the chemical layers detected by the TRACE-P aircraft. Although the RDF technique itself is not new, its application to boundary layer venting appears to be new. The procedure would be a useful real-time tool for flight planning during future atmospheric chemistry aircraft campaigns.

[80] Acknowledgments. We appreciate the many helpful conversations with various members of the TRACE-P science team. This research was sponsored by the NASA Tropospheric Chemistry Program.

\section{References}

Anthes, R. A., A cumulus parameterization scheme utilizing a one-dimensional cloud model, Mon. Weather Rev., 105, 270-286, 1977.

Anthes, R. A., and T. T. Warner, Development of hydrodynamic models suitable for air pollution and other mesometeorological studies, Mon. Weather Rev., 106, 1045-1078, 1978.

Bader, M. J., G. S. Forbes, J. R. Grant, R. B. E. Lilley, and A. J. Waters (Eds.), A Practical Guide for Interpreting Satellite and Radar Imagery, Cambridge Univ. Press, New York, 1995.

Bethan, S., G. Vaughan, C. Gerbig, A. Volz-Thomas, H. Richer, and D. A. Tiddeman, Chemical air mass differences near fronts, J. Geophys. Res., 103, 13,413-13,434, 1998.

Bieberbach, G., Jr., H. E. Fuelberg, A. M. Thompson, A. Schmitt, J. R. Hannan, G. L. Gregory, Y. Kondo, R. D. Knabb, G. W. Sachse, and R. W Talbot, Mesoscale numerical investigations of air traffic emissions over the North Atlantic during SONEX flight 8: A case study, J. Geophys. Res., 105, 3821-3832, 2000.

Browning, K. A., Conceptual models of precipitation systems, Weather Forecasting, 1, 23-41, 1986.

Browning, K. A., Organization of clouds and precipitation in extratropical cyclones, Extratropical Cyclones, The Erik Palmen Memorial Volume, edited by C. W. Newton and E. O. Holopainen, pp. 129-153, Am. Meteorol. Soc., Boston, Mass., 1990.

Browning, K. A., and T. W. Harrold, Air motions and precipitation growth in a wave depression, Q. J. R. Meteorol. Soc., 95, 288-309, 1969.

Browning, K. A., and J. Mason, Air motion and precipitation growth in frontal systems, Pure Appl. Geophys., 119, 577-593, 1981.

Carlson, T. N., Airflow through mid-latitude cyclones and the comma cloud pattern, Mon. Weather Rev., 108, 1498-1509, 1980.

Cohen, R. A., and C. W. Kreitzberg, Airstream boundaries in numerical weather simulations, Mon. Weather Rev., 125, 168-183, 1997.

Cooper, O. R., J. L. Moody, D. D. Parrish, M. Trainer, T. B. Ryerson, J. S. Holloway, G. Hubler, F. C. Fehsenfeld, S. J. Oltmans, and M. J. Evans, Trace gas signatures of the airstreams within North Atlantic cyclones: Case studies from the North Atlantic Regional Experiment (NARE '97) aircraft intensive, J. Geophys. Res., 106, 5437-5456, 2001.

Cotton, W. R., G. D. Alexander, R. Hertenstein, R. L. Walko, R. L. McAnelly, and M. Nicholls, Cloud venting-A review and some new global annual estimates, Earth Sci. Rev., 39, 169-206, 1995.

Donnell, E. A., D. J. Fish, E. M. Dicks, and A. J. Thorpe, Mechanisms for pollutant transport between the boundary layer and the free troposphere, J. Geophys. Res., 106, 7847-7856, 2001.

Doty, K. G., and D. J. Perkey, Sensitivity of trajectory calculations to the temporal frequency of wind data, Mon. Weather Rev., 121, 387-401, 1993. 
Draxler, R. R., The accuracy of trajectories during ANATEX calculations using dynamic model analyses versus rawinsonde observations, J. Appl. Meteorol., 30, 1446-1467, 1991

Dudhia, J., A nonhydrostatic version of the Penn State/NCAR mesoscale model: Validation tests and simulation of an Atlantic cyclone and cold front, Mon. Weather Rev., 121, 1493-1513, 1993.

Durran, D. R., and D. B. Weber, An investigation of the poleward edges of cirrus clouds associated with midlatitude jet streams, Mon. Weather Rev, 116, 702-714, 1988.

Esler, J. G., and P. H. Haynes, Transport and mixing between airmasses in cold frontal regions during Dynamics and Chemistry of Frontal Zones (DCFZ), J. Geophys. Res., 108(D4), 4142, doi:10.1029/2001JD001494, 2003.

Fuelberg, H. E., R. O. Loring Jr., M. V. Watson, M. C. Sinha, K. E. Pickering, A. M. Thompson, G. W. Sachse, D. R. Blake, and M. R. Schoelberl, TRACE-A - A trajectory intercomparison: 2. Isentropic and kinematic methods, J. Geophys. Res., 101, 23,927-23,939, 1996.

Fuelberg, H. E., J. R. Hannan, P. F. J. van Velthoven, E.V. Browell, G. Bieberbach Jr., R. D. Knabb, G. L. Gregory, K. E. Pickering, and H. B. Selkirk, A meteorological overview of the SONEX period, J. Geophys. Res., 105, 3633-3651, 2000.

Grant, W. B., et al., A case study of transport of tropical marine boundary layer and lower tropospheric air masses to the northern mid latitude upper troposphere, J. Geophys. Res., 105, 3757-3770, 2000.

Grell, G. A., J. Dudhia, and D. R. Stauffer, A description of the fifthgeneration Penn State/MCAR mesoscale model (MM5), Tech. Note NCAR/TN-398+STR, 117 pp., Nat. Cent. for Atmos. Res., Boulder, Colo., 1994.

Hannan, J. R., et al., Atmospheric chemical transport based on high-resolution model-derived winds: A case study, J. Geophys. Res., 105, 3807$3820,2000$.

Holton, J. R., P. H. Haynes, E. M. McIntyre, A. R. Douglass, R. B. Rood, and L. Pfister, Stratosphere-troposphere exchange, Rev. Geophys, 33, 403-439, 1995.

Jacob, D. J., et al., Transport and chemical evolution over the Pacific (TRACE-P) mission: Design, execution, and first results, J. Geophys. Res., 108(D20), 8781, doi:10.1029/2002JD003276, in press, 2003.

Jaffe, D., et al., Transport of Asian air pollution to North America, Geophys. Res. Lett., 26, 711-714, 1999.

Kaneyasu, N., K. Takeuchi, M. Hayashi, S.-I. Fujita, I. Uno, and H. Sasaki, Outflow patterns of pollutants from East Asia to the North Pacific in the winter monsoon, J. Geophys. Res., 105, 17361-17377, 2000.

Kuo, Y.-H., R. J. Reed, and S. Low-Nam, Thermal structure and airflow in a model simulation of an occluded marine cyclone, Mon. Weather Rev., 120, 2280-2297, 1992.

Lewis, J. M., and C. A. Crisp, Return flow in the Gulf of Mexico, part II: Variability in return-flow thermodynamics inferred from trajectories over the Gulf, J. Appl. Meteorol., 31, 882-899, 1992.

Lewis, J. M., C. M. Hayden, R. T. Merrill, and J. M. Schneider, GUFMEX: A study of return flow in the Gulf of Mexico, Bull. Am. Meteorol. Soc., 70, 24-29, 1989.

Martin, B. D., H. E. Fuelberg, N. J. Blake, J. H. Crawford, J. A. Logan, D. R. Blake, and G. W. Sachse, Long range transport of Asian outflow to the equatorial Pacific, J. Geophys. Res., 108(D2), 8233, doi:10.1029/2001JD001418, 2002.

Martin, J. E., Quasigeostrophic forcing of ascent in the occluded sector of cyclones and the trowal airstream, Mon. Weather Rev., 127, 70-88, 1999.

Mass, C. F., and D. M. Schultz, The structure and evolution of a simulated mid-latitude cyclone over land, Mon. Weather Rev., 121, 889-917, 1993.

McNeal, R. J., J. P. Mugler Jr., R. C. Harriss, and J. M. Hoell Jr., NASA Global Tropospheric Experiment, Eos Trans. AGU, 64, 561-562, 1984. Schultz, D. M., Reexamining the cold conveyor belt, Mon. Weather Rev, 129, 2205-2225, 2001.
Seaman, N. L., and S. A. Michelson, Mesoscale meteorological structure of a high-ozone episode during the 1995 NARSTO-Northeast study, J. Appl. Meteorol., 39, 384-398, 2000.

Stauffer, D. R., and N. L. Seaman, Use of four-dimensional data assimilation in a limited-area mesoscale model, part I. Experiments with synopticscale data, Mon. Weather Rev., 118, 1250-1277, 1990.

Stauffer, D. R., and N. L. Seaman, Multiscale four-dimensional assimilation, J. Appl. Meteorol., 33, 416-434, 1994.

Stauffer, D. R., N. L. Seaman, and F. S. Binkowski, Use of four-dimensional data assimilation in a limited area mesoscale model, part II, Effects of data assimilation within the planetary boundary layer, Mon. Weather Rev., 119, 734-754, 1991.

Stohl, A., A 1-year Lagrangian "climatology" of airstreams in the northern hemisphere troposphere and lowermost stratosphere, J. Geophys. Res., 106, 7263-7279, 2001.

Stohl, A., and P. Seibert, The accuracy of trajectories as determined from the conservation of meteorological tracers, Q. J. R. Meteorol. Soc., 124, 1465-1484, 1998.

Stohl, A., and T. Trickl, A textbook example of long-range transport: Simultaneous observation of ozone maxima of stratospheric and North American origin in the free troposphere over Europe, J. Geophys. Res., 104, 30,445-30,462, 1999.

Stohl, A., G. Wotawa, P. Seibert, and H. Hromp-Kolb, Interpolation errors in wind fields as a function of spatial and temporal resolution and their impact on different types of kinematic trajectories, J. Appl. Meteorol., 34, 2149-2165, 1995.

Streets, D. G., et al., A year-2000 inventory of gaseous and primary aerosol emissions in Asia to support TRACE-P modeling and analysis, J. Geophys. Res., 108(D21), 8809, doi:10.1029/2002JD003093, in press, 2003.

Sutton, R., H. Maclean, R. Swinbank, A. O'Neill, and F. W. Taylor, High resolution tracer fields estimated from satellite observations using Lagrangian trajectory calculations, J. Atmos. Sci., 51, 2995-3005, 1994.

U.S. Department of Energy (DOE), International Energy Outlook (IEO), 1997, Energy Inf. Admin., U.S. Dept. of Energy, Washington, D.C., 1997. (Available at http://www.eia.doe.gov/oiaf/ieo97)

Warner, T. T., R. A. Peterson, and R. E. Treadon, A tutorial on lateral boundary conditions as a basic and potentially serious limitation to regional numerical weather prediction, Bull. Am. Meteorol. Soc., 78, 25992617, 1997.

Wernli, H., A Lagrangian-based analysis of extratropical cyclones. II: A detailed case study, Q. J. R. Meteorol. Soc., 123, 1677-1706, 1997.

Wernli, H., and H. C. Davies, A Lagrangian-based analysis of extratropical cyclones. I: The method and some applications, $Q$. J. R. Meteorol. Soc., 123, 467-489, 1997.

Young, M. V., Investigation of a cyclogenesis event, 26-29 July 1988, using satellite imagery and numerical model diagnostics, Meteorol. Mag., 118, 185-196, 1989.

Zhang, D.-L., and R. A. Anthes, A high-resolution model of the planetary boundary layer: Sensitivity tests and comparisons with SESAME-79 data, J. Appl. Meteorol., 21, 1594-1609, 1982.

D. R. Blake, Department of Chemistry, University of California, Irvine, Irvine, CA 92697-2025, USA. (drblake@uci.edu)

J. H. Crawford, NASA Langley Research Center, Hampton, VA 236810001, USA. (j.h.crawford@larc.nasa.gov)

H. E. Fuelberg, Department of Meteorology, Florida State University, Tallahassee, FL 32306-4520, USA. (fuelberg@met.fsu.edu)

J. R. Hannan, Northrop Grumman IT, DES, 6940 South Kings Highway, Suite 210, Alexandria, VA 22310, USA. (john.hannan@ngc.com)

G. W. Sachse, Aerospace Electronic Systems Division, NASA Langley Research Center, MS472, Hampton, VA 23681-2199, USA. (g.w.sachse@) larc.nasa.gov) 